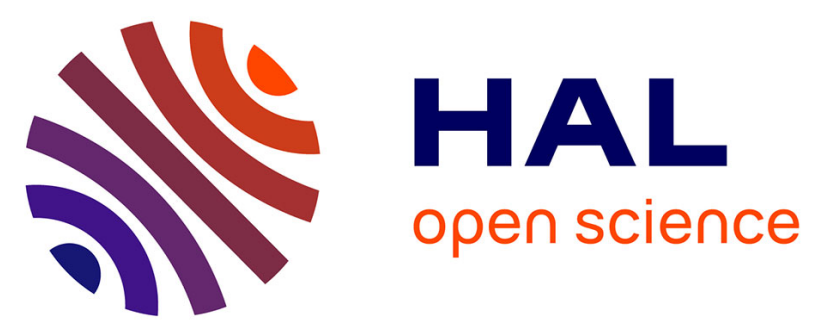

\title{
Preparation and dielectric properties of poly(acrylonitrile- co -2,2,2-trifluoroethyl methacrylate) materials via radical emulsion copolymerization
}

Amal Kadimi, Hamid Kaddami, Zoubeida Ounaies, Youssef Habibi, Reiner Dieden, Bruno Ameduri, Mustapha Raihane

\section{To cite this version:}

Amal Kadimi, Hamid Kaddami, Zoubeida Ounaies, Youssef Habibi, Reiner Dieden, et al.. Preparation and dielectric properties of poly(acrylonitrile- co -2,2,2-trifluoroethyl methacrylate) materials via radical emulsion copolymerization. Polymer Chemistry, 2019, 10 (40), pp.5507-5521. 10.1039/c9py00673g . hal-03098314

\section{HAL Id: hal-03098314 https://hal.science/hal-03098314}

Submitted on 5 Jan 2021

HAL is a multi-disciplinary open access archive for the deposit and dissemination of scientific research documents, whether they are published or not. The documents may come from teaching and research institutions in France or abroad, or from public or private research centers.
L'archive ouverte pluridisciplinaire HAL, est destinée au dépôt et à la diffusion de documents scientifiques de niveau recherche, publiés ou non, émanant des établissements d'enseignement et de recherche français ou étrangers, des laboratoires publics ou privés. 
Preparation and dielectric properties of poly(acrylonitrile-co2,2,2-trifluoroethyl methacrylate) materials via radical emulsion copolymerization

\author{
Amal Kadimi, ${ }^{1}$ Hamid Kaddami, ${ }^{1}$ Zoubeida Ounaies, ${ }^{2}$ Youssef Habibi, ${ }^{3}$ Reiner Dieden, ${ }^{3}$ \\ Bruno Ameduri, ${ }^{* *}$ Mustapha Raihane ${ }^{1^{*}}$ \\ ${ }^{1}$ Laboratory of Organometallic and Macromolecular Chemistry-Composite Materials. Faculty \\ of Sciences and Techniques, Cadi Ayyad University, Avenue Abdelkrim El khattabi, B.P. \\ 549, 40000 Marrakech, Morocco \\ ${ }^{2}$ Electroactive Materials Characterization Lab, Department of Mechanical \& Nuclear \\ Engineering, Pennsylvania State University, 137 Reber Building, University Park, \\ Pennsylvania 16802, USA \\ 3 Materials Research and Technology (MRT), Luxembourg Institute of Science and \\ Technology (LIST), Belval Innovation Campus,5, avenue des Hauts-Fourneaux, L-4362 \\ Esch-sur-Alzette, Luxembourg \\ ${ }^{4}$ Institute Charles Gerhardt, UMR 5253 CNRS, University of Montpellier, ENSCM, Place \\ Eugène Bataillon, 34095 Cedex 5 Montpellier, France. \\ * Corresponding authors: \\ M. Raihane (m.raihane@uca.ma), \\ B. Ameduri (bruno.ameduri@enscm.fr)
}




\section{Abstract}

Radical emulsion copolymerization of acrylonitrile (AN) with 2,2,2-trifluoroethyl methacrylate (MATRIF) and their homopolymerization initiated by potassium persulfate (KPS) were studied. The resulting poly(AN-co-MATRIF) copolymers were characterized by ${ }^{1} \mathrm{H},{ }^{13} \mathrm{C}$ NMR and IR spectroscopies and their compositions determined by ${ }^{1} \mathrm{H}$ NMR. The kinetics of radical copolymerization of AN with MATRIF was investigated from several experiments achieved at $75^{\circ} \mathrm{C}$ from initial $[\mathrm{AN}]_{0}:[\mathrm{MATRIF}]_{0}$ molar ratios ranging between $15 / 85$ and $85 / 15$. The Extended Kelen-Tüdos law enabled to assess the reactivity ratios of both comonomers $\left(\mathrm{r}_{1}=\mathrm{r}_{\mathrm{AN}}=0.09, \mathrm{r}_{2}=\mathrm{r}_{\mathrm{MATRIF}}=0.47\right.$ at $\left.75^{\circ} \mathrm{C}\right)$. Their product, $\mathrm{r}_{1} \mathrm{xr}_{2}=0.04$ close to zero, anticipates a certain tendency to an alternated structure for poly(AN-co-MATRIF) copolymer with homosequences based on both monomers depending on their molar feed compositions. This was also confirmed by the Igarashi's and Pyun's laws which revealed the presence of AN-MATRIF, AN-AN, and MATRIF-MATRIF dyads. The glass transition temperature values, $\mathrm{Tg}$, of these copolymers showed a slightly increase from 75 to $78{ }^{\circ} \mathrm{C}$ as the MATRIF molar percentage decreased from 82 to 34 mol.\% in the copolymer. Dynamic mechanical analysis (DMA) thermogramms of poly(AN-co-MATRIF) 75/25 copolymer (where 75 and 25 are the feed molar percentages of AN and MATRIF, respectively) showed a second broad signal attributed to the local relaxation corresponding to the homosequences. Both poly(AN-co-MATRIF) copolymer films were dielectrically characterized over a frequency range between $20 \mathrm{~Hz}$ and $1 \mathrm{MHz}$, and in a temperature range from 20 to $120{ }^{\circ} \mathrm{C}$ and then compared to the corresponding poly(MATRIF) hompolymer. The dominating relaxation process detected in both materials is the $\alpha$-relaxation, associated with the dynamic glass transition. The dielectric increment, $\Delta \varepsilon$, and dielectric breakdown, $\mathrm{E}_{\mathrm{b}}$, were calculated and the composition of $\mathrm{AN}$ in the copolymers (and polarity)-permittivity relationship was established. Therefore, the synthesis strategy adopted can tailor the dielectric properties of copolymers by changing the monomer feed ratios with suitable film forming. This improvement of dielectric properties was observed when the composition of AN was higher in the copolymers and therefore opened new applications of the thin films of poly(AN-coMATRIF) copolymers for energy capacitor devices of amorphous copolymers. 


\section{Introduction}

High dielectric constant polymers are becoming crucial components in advanced electronic devices, such as memory and gate dielectrics for integrated circuits, stationary power generation, and miniature capacitors for telecommunication. ${ }^{1}$ Polymers containing cyano (nitrile) groups directly attached to the main chain are of potential interest for these developments owing to the large dipole moments that can be induced along the macromolecular chain. ${ }^{2}$ Vinylidene cyanide (VCN) has often been employed in the preparation of high polar polymers as a useful starting monomer. ${ }^{3,4}$ Electric applications of VCN were discovered by Miyata et al. ${ }^{5,6}$ or from the NASA, ${ }^{7}$ and these authors observed piezoelectric properties of amorphous copolymers of VCN with vinyl acetate.

Other polymers based on commercially available cyano monomers such as acrylonitrile have been used. In fact, acrylonitrile (AN) homo- and copolymers are one of the most important commercially available materials showing features in academics and widely used as reinforcing components in automobile, aerospace and others industries. The dielectric behavior of poly(acrylonitrile), PAN, has been comprehensively studied. ${ }^{8}$ Thin film transistors were achieved from PAN homopolymer. ${ }^{9}$ PAN exhibits a good processability and electrochemical stability, but it is brittle because of adjacent cyano groups. ${ }^{10}$ This drawback can be avoided by forming copolymers through copolymerization with suitable comonomers. Therefore, copolymers based on AN with $\alpha$-cyanovinyl acetate ${ }^{11}$ and methyl $\alpha$-acetoxy acrylate ${ }^{12}$ have been synthesied by radical copolymerization and the resulting copolymers were characterized by IR, NMR spectroscopies, SEC, DSC and TGA. Their molecular dynamics were studied by dielectric spectroscopy. ${ }^{13,14}$ AN copolymerized with vinyl acetate or isopropenyl acetate and vinyl formate ${ }^{15}$ and the resulting copolymers displayed interesting pyroelectric properties. $^{16}$

Fluorinated polymers are niche macromolecules that play an essential role in modern life, ${ }^{17}$ and due to the properties of fluorine, they exhibit unique and remarkable properties. Their applications span from engineering thermoplastics to elastomers for the chemical process, automotive and aeronautics industries, weatherproof coatings, biomedical materials, separators, electrolytes, binders for Li batteries, exchange membranes in fuel cells, and many more. $^{18-22}$

It is well-known that fluorinated poly(methacrylate)s, rich in trifluoromethyl groups, exhibit superior performance of chemical inertness, excellent weatherability, low refractive index, and special surface properties. $^{20,22-25}$ Poly(2,2,2-trifluoroethyl methacrylate), poly(MATRIF), 
is an important class of such materials, since it possess excellent water-repellent capacity, ${ }^{26}$ good resistance to oxygen permeability and stain, ${ }^{27}$ and lower water-absorption. ${ }^{28}$ It has been extensively used in high-performance coatings, ${ }^{29,} 30$ optical fibers, ${ }^{31}$ and other applications. Dielectric relaxation studies carried out on a series of poly(fluoroalkyl methacrylate)s indicate the occurrence of $\alpha$ and $\gamma$ relaxations assigned to segmental reorientation and local molecular motions of fluoroalkyl side groups above and below $\mathrm{T}_{\mathrm{g}}$, respectively. ${ }^{32}$ These polymers exhibit low dielectric constants. In this context, one the promising method for the improvement of dielectric properties of fluorinated poly(methacrylates) is based on the introduction of additional dipolar groups by copolymerization of fluorinated methacrylates with cyano comonomers, in order to increase the polarity of the polymer chain (Theory of Frohlich ${ }^{33}$ ). A series of amorphous copolymers of MATRIF with cyano monomers (i.e methacrylonitrile, MAN, methylvinylidene cyanide, MVCN) were prepared by free radical copolymerization in solution, and their microstructural, reactivity ratios, thermal and dielectric properties were investigated. ${ }^{34,35}$ However, this homogenous copolymerization yielded lower molar mass-copolymers ranging between 13000 et 24000 g.mol ${ }^{-1}$. The films obtained by casting were mechanically poorly stable. As a further expansion of this investigation on the synthesis and characterization of new dielectric copolymers containing cyano and fluoroalkyl substituents, a nearly alternating copolymer of MATRIF with VCN was also prepared by bulk radical copolymerization. Its microstructural features were highlighted by NMR spectroscopy while the reactivity ratios of the both monomers were assessed from both $Q$ - $e$ Alfrey-Price parameters and Jenkins's Scheme. ${ }^{36}$ The thermal degradation kinetics by dynamic and isothermal methods of poly(VCN-co-MATRIF) copolymers were also studied. ${ }^{37}$ SEC analysis of such copolymers indicated higher molar masses $\left(\mathrm{M}_{\mathrm{n}}\right.$ up to $\left.136000 \mathrm{~g} \cdot \mathrm{mol}^{-1}\right)$ with good forming-film properties. However, in contrast to $\mathrm{AN}$ (commercial monomer), $\mathrm{VCN}$ is difficult to prepare; its synthesis occurs in two steps, the second one being a pyrolysis at ca. $250{ }^{\circ} \mathrm{C}$. In addition, this is highly reactive and moisture sensitive. More recently, results of the dielectric characterization were reported. ${ }^{38}$ Compared to MATRIF homopolymer as a reference, the introduction of polar VCN units results in an increase of both dielectric constant and glass transition temperature. This behaviour is required for bringing piezo- and pyroelectricity in amorphous polymers. However, the difficulty to synthesise VCN monomer and its instability limit the preparation of the poly(VCN-alt-MATRIF) copolymer comparatively to poly(AN-co-MATRIF) ones.

Appropriate techniques must be selected and polymerization conditions should be optimized to improve the quality of products when these high performance fluorinated cyano acrylic 
polymers are to be synthesised (i.e suitable film forming properties for dielectric measurement). One of the most common methods to reach desired properties is emulsion polymerization. ${ }^{39}$ Faster polymerization rates, high molar mass products, and a nontoxic polymerization medium are the key advantages of the emulsion polymerization. ${ }^{40}$ Copolymers from such a polymerization have been widely used for coatings of substrates (leather, paper, textile, fabrics) and for paints, carpets, adhesives, and biomedical industries. ${ }^{41} 39$ The latex polymers obtained were usually used to process mechanically stable films and also to favor nanocharge /polymer composites by casting. ${ }^{42-45}$

However, to the best our knowledge, the emulsion radical copolymerization of AN with MATRIF of different compositions has never been reported. Therefore, this article describes such a reaction involving both cyano and fluorinated commercially available comonomers. After purification, their compositions were assessed by ${ }^{1} \mathrm{H}$ NMR. The kinetic of the emulsion radical copolymerization was also investigated to determine their reactivity ratios. The microstructure and stereosequence distribution and thermal properties of the resulting poly(AN-co-MATRIF) copolymers were also studied as well as their dielectric properties. The polarity of polymer chain (incorporation of the rigid and polar AN units)-dielectric properties relationship was also established. Finally, the dielectric strength, and breakdown strength were calculated and discussed.

\section{Experimental}

\subsection{Materials}

Acrylonitrile (AN) is commercially available product from Aldrich-Sigma while 2,2,2-trifluoroethyl methacrylate (MATRIF) was kindly supplied by Tosoh Finechemicals Corp, and were distilled, then stored in a fridge at $5{ }^{\circ} \mathrm{C}$ prior to use. Sodium dodecyl sulfate (SDS), potassium persulfate (KPS), sodium bicarbonate $\left(\mathrm{NaHCO}_{3}\right)$, aqueous aluminum sulfate $\left(\mathrm{Al}_{2}\left(\mathrm{SO}_{4}\right)_{3}, 6 \mathrm{H}_{2} \mathrm{O}\right)$, sulfuric acid $(95 \%)$, N,N-dimethylformamide (DMF) were purchased from Sigma-Aldrich and used without further purification.

\subsection{Synthesis of copolymers}

The emulsion radical polymerization of AN and MATRIF was carried out in a glass reactor equipped with a mechanical stirrer and a reflux condenser. In a typical copolymerization, the surfactant (sodium dodecyl sulfate, SDS) (0.2 g, $0.6 \mathrm{mmol}$ ), buffer (sodium hydrogen carbonate, $\left.\mathrm{NaHCO}_{3}\right)(0.037 \mathrm{~g}, 0.44 \mathrm{mmol})$, deionized water $(25 \mathrm{~g})$ and the AN and MATRIF 
( $7 \mathrm{~g})$ were introduced into the reactor. The mixture was purged with nitrogen for $1 \mathrm{~h}$ and then placed in a thermostatic oil bath. When the targeted temperature reached $80{ }^{\circ} \mathrm{C}$, KPS initiator (0.06 g, $2.4 \mathrm{mmol})$, previously dissolved in deionized water, was transferred into the mixture. This medium was mechanically stirred at $75{ }^{\circ} \mathrm{C}$ for $24 \mathrm{~h}$. After reaction, and in order to promote the separation of the polymer from the aqueous phase, a solution of $10 \mathrm{wt} \%$ of aqueous aluminum sulfate $\left(\mathrm{Al}_{2}\left(\mathrm{SO}_{4}\right)_{3}, 6 \mathrm{H}_{2} \mathrm{O}\right)$ was added to the obtained latex. Then, the resulting copolymer was filtered, washed with distilled water to remove any residual surfactant, and then rinsed several times with methanol. The poly(AN-co-MATRIF) copolymers were further dried under vacuum at $60^{\circ} \mathrm{C}$ for $24 \mathrm{~h}$ until constant weight. The obtained copolymers (white powders) were weighed to assess the yield and then characterized by appropriate techniques as explained below.

Several copolymerizations, displayed in Scheme 1, were carried out from different initial comonomers molar ratios ranging between 15 and $85 \mathrm{~mol} \%$. The resulting copolymers were referred to as poly(AN-co-MATRIF) $\mathrm{n} / \mathrm{m}$, where $\mathrm{n}$ and $\mathrm{m}$ indicate the molar percentages of AN and MATRIF in the feed, respectively.

The poly(MATRIF) and poly(AN) homopolymers were also synthesized to be used as a reference materials according to the same preparation route.

$$
\mathrm{n}
$$<smiles>C=CC#N</smiles>

AN

MATRIF

Schema 1 Radical emulsion copolymerization of AN with MATRIF initiated by KPS in deionized water leading to poly(AN-co-MATRIF) copolymers (SDS stands for sodium dodecyl sulfate used as surfactant)

\subsection{Preparation of (co)polymers films}

The polymer was dissolved in DMF (20\% wt/v) using a magnetic stirrer for $2 \mathrm{~h}$ at $60{ }^{\circ} \mathrm{C}$, and the mixture was degassed under vacuum. The polymer films were prepared by casting a DMF solution of polymer on a smooth glass plate. Then, the films were first evaporated at $45{ }^{\circ} \mathrm{C}$ for $12 \mathrm{~h}$ and then under vacuum at $100{ }^{\circ} \mathrm{C}$ for $4 \mathrm{~h}$.

\subsection{Characterization techniques}


Infrared spectroscopy (FTIR) analyses were performed in transmittance mode with a VERTEX spectrometer 70 on pellets samples prepared from $1 \%$ of polymer powder and $\mathrm{KBr}$. The spectra were scanned within the $400-4000 \mathrm{~cm}^{-1}$ range.

Nuclear magnetic resonance spectroscopy. ${ }^{1} \mathrm{H}$ and ${ }^{13} \mathrm{C}$ NMR spectra were recorded using Bruker Avance spectrometer operating at 600 and $150.8 \mathrm{MHz}$, respectively, using a pulse width of $53^{\circ}$, acquisition time $1.3 \mathrm{sec}$, delay time $1.5 \mathrm{sec}, 18000$ transients for the ${ }^{13} \mathrm{C}$ spectra. Analyses were recorded in deuterated N,N-dimethylformamide (DMF- $\mathrm{d}_{7}$ ) at room temperature.

Differential Scanning Calorimetry (DSC) experiments were performed using TA instruments model Q-20to to observe thermal transitions and crystallinity in the material. The samples were heated at $10{ }^{\circ} \mathrm{C} \mathrm{min}^{-1}$ from room temperature up to $120^{\circ} \mathrm{C}$ under a nitrogen atmosphere. Dynamic mechanical analysis (DMA) experiments were recorded using RSA G2 TA instrument to analyze the thermomechanical properties of the copolymers samples, the temperature scan runs from room temperature up to $160{ }^{\circ} \mathrm{C}$ at a scanning rate of $2{ }^{\circ} \mathrm{C} \min ^{-1}$.

Dielectric permittivity measurements were carried out using a LCR meter coupled with a lock-in amplifier (Stanford Research Systems). A Kurt J. Lesker Evaporator was used to deposit silver electrodes $(100 \mathrm{~nm})$ on top of the polymer films for electrical characterization (electrodes with a diameter of $1 \mathrm{~cm}$ and a thickness of $100 \mathrm{~nm}$ ). All poly(AN-co-MATRIF) copolymers and poly(MATRIF) homopolymer were dielectrically characterized over a frequency range from $20 \mathrm{~Hz}$ to $1 \mathrm{MHz}$. The temperature ranged between 20 to $120{ }^{\circ} \mathrm{C}$, spanning well below an above the glass temperature transition.

Electrical breakdown measurements were performed using a Trek high voltage amplifier in golden oil. On the surface of each film around 30 different points were selected and high voltage was applied to each point with a ramp rate of $500 \mathrm{~V} / \mathrm{s}$.

\section{Results and discussion}

\subsection{Synthesis of poly(AN-co-MATRIF) copolymers and Spectroscopic characterizations}

The emulsion radical copolymerizations of both these monomers was carried out in water at $75^{\circ} \mathrm{C}$ initiated by potassium persulfate (KPS) (Entries 1-5, Table 1). The reaction time was set at $24 \mathrm{~h}$. The copolymerization was designed to cover the whole range of compositions including also the synthesis of both homopolymers. After reaction and purification by 
coagulation, the chemical structure of poly(AN-co-MATRIF) copolymers was elucidated by FTIR and ${ }^{1} \mathrm{H}$ and ${ }^{13} \mathrm{C}$ NMR spectroscopies. Finally, their thermal (DSC), dynamic mechanical analysis (DMA) and dielectric properties were also studied.

All FTIR spectra of the copolymers show the characteristic bands of the two monomers incorporated in the copolymers. Figure S1 (in the electronic supporting information, ESI) displays the IR spectrum of poly(AN-co-MATRIF) copolymer prepared from a feed molar ratio of $[\mathrm{AN}]_{0}:[\mathrm{MATRIF}]_{0}=50: 50$ (Entry E3, Table 1). All FTIR discussions are reported in ESI.

Table 1: Experimental conditions and results of emulsion radical copolymerization of AN with MATRIF initiated by KPS at $75^{\circ} \mathrm{C}$ in deionized water

\begin{tabular}{|c|c|c|c|c|}
\hline Entry & Copolymers $^{\text {a) }}$ & $\begin{array}{c}\text { AN (mol. \%) } \\
\text { in feed }{ }^{\text {b) }}\end{array}$ & $\begin{array}{c}\text { AN (mol. \%) } \\
\left.\text { in copolymer }{ }^{c}\right)\end{array}$ & $\begin{array}{l}\text { Yield } \\
\text { (wt \%) }\end{array}$ \\
\hline E1 & Poly(AN-co-MATRIF) 15/85 & 15 & 19 & 58 \\
\hline E2 & Poly(AN-co-MATRIF) 25/75 & 25 & 28 & 54 \\
\hline E3 & Poly(AN-co-MATRIF) 50/50 & 50 & 44 & 60 \\
\hline E4 & Poly(AN-co-MATRIF) 75/25 & 75 & 60 & 62 \\
\hline E5 & Poly(AN-co-MATRIF) 85/15 & 85 & 66 & 54 \\
\hline
\end{tabular}

The purified copolymers, as white powders, were also characterized by ${ }^{1} \mathrm{H}$ and ${ }^{13} \mathrm{C}$ NMR spectroscopies. The assignments of chemical shifts were deduced from the comparison of those of poly(AN) and poly(MATRIF) hompolymers (Figure S12, in the electronic supporting information, ESI), with those of the copolymers based on MATRIF. ${ }^{34,36,46}$ All the ${ }^{1} \mathrm{H}$ NMR spectra of poly(AN-co-MATRIF) copolymer recorded in DMF- $\mathrm{d}_{7}$ exhibit the chemical shifts of different protons in the copolymers. As examples, Figure 1 supplies the ${ }^{1} \mathrm{H}$ and ${ }^{13} \mathrm{C} \mathrm{NMR}$ spectra of poly(AN-co-MATRIF) copolymers corresponding to Entries E5 and E1, respectively (Table 1$)$. 
Figure S2 (ESI) displays the ${ }^{1} \mathrm{H}$ NMR spectra of poly(AN-co-MATRIF) copolymers (Entries 1-4, Table 1)

These spectra display the characteristic signals of both comonomers in the copolymer, centered at $4.8 \mathrm{ppm}$ and in the 2.7-3.4 ppm range, attributed to methylene of ester group (-O$\left.\mathrm{CH}_{2}-\mathrm{CF}_{3}\right)$ in MATRIF and methine proton $(-\mathrm{CH}-\mathrm{CN})$ of $\mathrm{AN}$, respectively. The methylene groups from the backbone (assigned to both AN and MATRIF units) gave multiplets between 1.5 and $2.4 \mathrm{ppm}$. The methyl protons of MATRIF led to a broad signal ranging between 0.8 and $1.5 \mathrm{ppm}$ linked to the tacticity of such a methacrylate. 


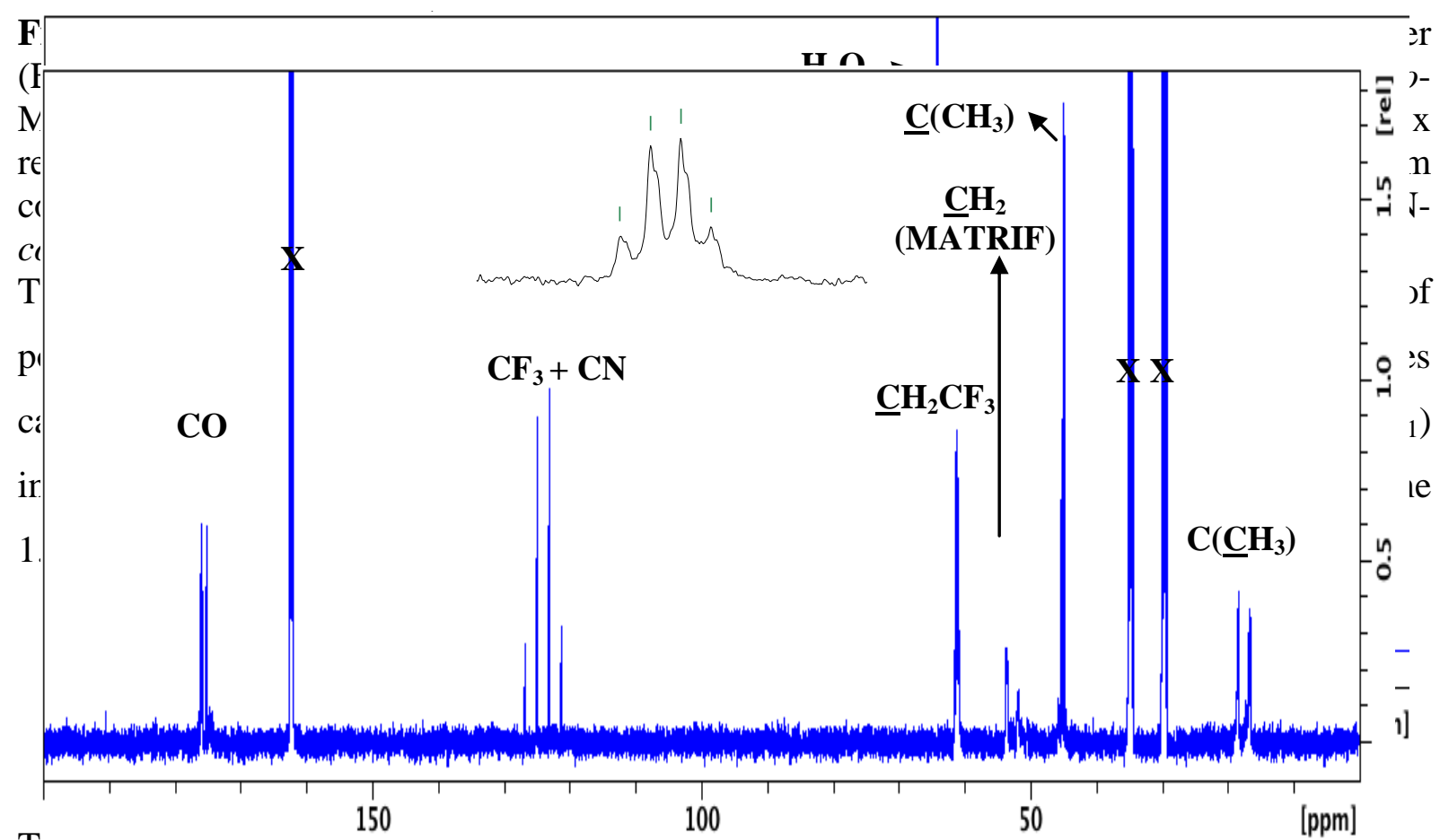

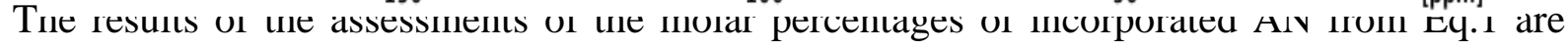
listed in Table 1.

The ${ }^{13} \mathrm{C}$ NMR spectrum of poly(AN-co-MATRIF) (Figure 1) display the characteristic signals in the 121-127 ppm range, assigned to $\mathrm{CF}_{3}\left({ }^{1} \mathrm{~J}_{\mathrm{C}-\mathrm{F}}=280 \mathrm{~Hz}\right)$ and $\mathrm{CN}$ groups ${ }^{34,36}$ while that of $\mathrm{C}=\mathrm{O}$ group of MATRIF signal is centered at $175 \mathrm{ppm}$. In addition, the $-\mathrm{CH}_{2} \mathrm{CF}_{3},-\underline{\mathrm{CH}_{2}}$ backbone, $-\underline{\mathrm{C}}\left(\mathrm{CH}_{3}\right)$ and $\mathrm{C}\left(\underline{\mathrm{CH}}_{3}\right)$ signals of MATRIF units are observed at $61,53,45$ and 18 ppm, respectively. ${ }^{34}$ The expanded resonance of the $-\underline{\mathrm{CH}_{2}} \mathrm{CF}_{3}$ group in poly(AN-co-MATRIF) copolymer showed four broad peaks attributed to the C-F coupling $\left({ }^{2} \mathrm{~J}_{\mathrm{C}-\mathrm{F}}=36 \mathrm{~Hz}\right)$. Finally, the methylene $\left(-\underline{C H}_{2}\right)$ and methine $(-\underline{C} H-C N)$ of $A N$ units in backbone gave signals centered at 35 and 28 ppm, respectively, overlapping with those of DMF.

\subsection{Kinetics of radical emulsion copolymerization of AN and MATRIF at high conversion}

Monomer reactivity ratios are useful parameters to predict the copolymer compositions. The kinetics of radical copolymerization of AN with MATRIF was investigated from five experiments achieved at $75{ }^{\circ} \mathrm{C}$ from initial $[\mathrm{AN}]_{0}:[\mathrm{MATRIF}]_{0}$ molar ratios ranging between 15:85 and 85:15 (Entries 1-5, Table 1). Several laws, based also on the Mayo-Lewis composition model, can be used to determine these ratios. Finemann-Ross ${ }^{47}$ and Kelen Tudos' laws ${ }^{48}$ are the most popular linear methods to calculate the reactivity ratios. They have the potential to be used at low conversion $(<10-15 \%)$. However, the Extended Kelen- 
Tüdos (EKT) model is a linear model that can be applied at high monomer conversion to determine the reactivity ratios and subsequent copolymer microstructure. We The Extended Kelen-Tüdos model (EKT) ${ }^{49,50}$ was chosen to assess the reactivity ratios of $\mathrm{AN}\left(\mathrm{r}_{1}\right)$ and MATRIF $\left(\mathrm{r}_{2}\right)$ at high conversion (ranging between 54 and 62\%, Table 1). The details of this model (equations and its conversion validity limits) are given in the ESI, and the results are supplied in Table S2.

Hence, plotting $\eta$ versus $\xi$ gave a straight line (Figure 2), the slope of which led to $r_{1}=r_{A N}=0.09 \pm 0.01$ while the intercept supplies $r_{2}=r_{\text {MATRIF }}=0.47 \pm 0.08$ at $75{ }^{\circ} \mathrm{C}$.

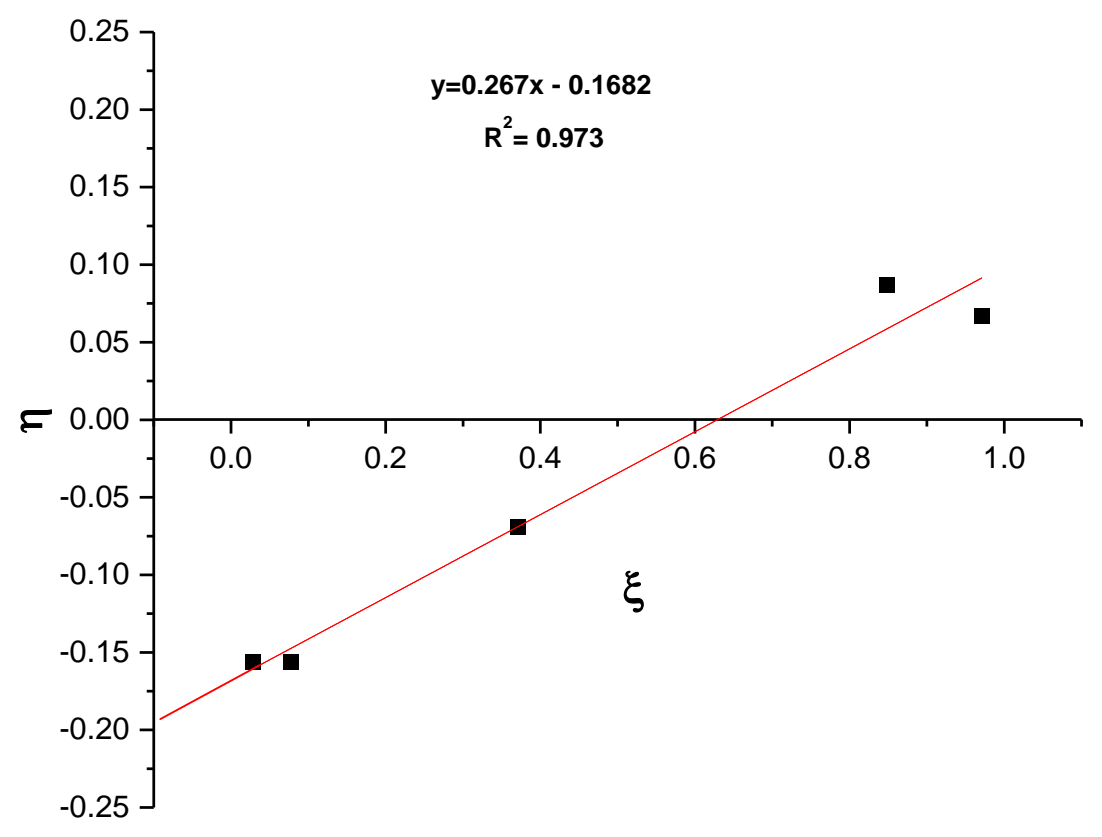

Figure $2 \eta$ versus $\xi$ for the Extended Kelen-Tüdos plot of the radical emulsion copolymerization of AN and MATRIF at $75{ }^{\circ} \mathrm{C}$

Their product $\mathrm{r}_{1} \mathrm{xr}_{2}=0.04$, being close to zero, may anticipate some random poly(AN-coMATRIF) copolymers with a certain tendency to alternated structures containing homosequences of both comonomers depending on their feed molar compositions. In fact, $\mathrm{r}_{2}$ is higher than $r_{1}$ indicating that the MATRIF radicals are more reactive than those based on AN in the formation of homosequence during the radical copolymerization inside the alternating blocks. The presence of a significant fraction of MATRIF-MATRIF or AN-AN homosequences could not neglected and depends on the molar fraction of MATRIF or AN in the feed. In fact, according to the study of stereosequence distribution using Igarashi's law 
(Section 3.3. Table 2), the tendency toward alternation is more important (ranging between 64 and 78\%) when the feed molar ratio of MATRIF varies between 15 and $50 \%$ (Entries E3E4, Tables 1 and 2), the $\mathrm{M}_{\mathrm{AN}}-\mathrm{M}_{\mathrm{AN}}$ homosequence is ranging between 34 and $5 \%$. In addition, the possible compositional drift can also be taken into account from the relatively high conversion. ${ }^{36}$

Besides, it is of interest to compare such obtained reactivity ratios with those determined from the copolymerization achieved in a homogenous medium. In fact, the solution copolymerization of AN and MATRIF performed in acetonitrile was reported in the literature. $^{34}$ The $Q$-e Alfrey-Price parameters of $\mathrm{AN}\left(\mathrm{Q}_{1}=0.48, \mathrm{e}_{1}=1.24\right)$ and MATRIF $\left(\mathrm{Q}_{2}=1.13, \mathrm{e}_{2}=0.98\right)$ were used to access to their reactivity ratios $\left(\mathrm{r}_{1}=\mathrm{r}_{\mathrm{AN}}=0.31\right.$ and $\mathrm{r}_{2}=$ $\mathrm{r}_{\text {MATRIF }}=3.04$ at $\left.80{ }^{\circ} \mathrm{C}\right)$. The product $\left(\mathrm{r}_{1} \mathrm{xr}_{2}\right)$ being close to 1 , explains the statistical structure of poly(AN-co-MATRIF) copolymers.

\subsection{Microstructure and stereosequence distribution}

The microstructure of the obtained poly(AN-co-MATRIF) copolymers is of great use in predicting copolymer properties. The Igarashi theory ${ }^{51}$ was used to calculate the statistical distribution of $\mathrm{M}_{\mathrm{MATRIF}}-\mathrm{M}_{\mathrm{MATRIF}}, \mathrm{M}_{\mathrm{AN}}-\mathrm{M}_{\mathrm{AN}}$ and $\mathrm{M}_{\mathrm{MATRIF}}-\mathrm{M}_{\mathrm{AN}}$ dyads from the following equations:

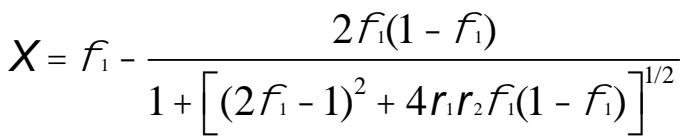

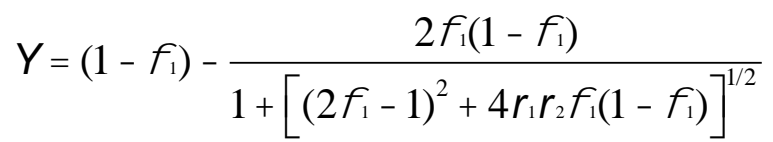

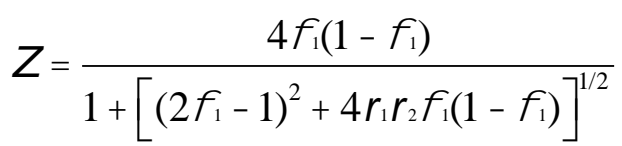

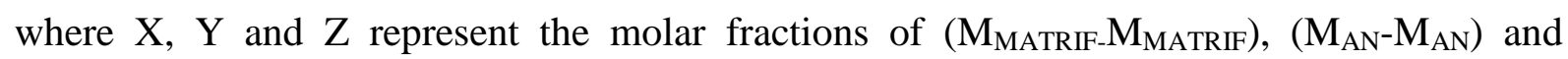
$\left(\mathrm{M}_{\mathrm{MATRIF}}-\mathrm{M}_{\mathrm{AN}}\right)$ sequences in the copolymers, respectively; 1 designates the molar fraction of MATRIF in the copolymer, while $r_{1}$ and $r_{2}$ stand for the reactivity ratios of AN and MATRIF calculated by Extended Kelen-Tüdos method at higher conversion. This method enables to calculate the fractions of oligo(AN) and oligo(MATRIF) microblocks and alternation units in the copolymers versus the reactivity ratio and copolymer composition. The 
monomer distribution for the obtained poly(AN-co-MATRIF) copolymers are presented in Table 2.

This table reveals that the tendency to alternation structures is observed when the feed molar composition of $\mathrm{AN}$ is higher than or equal to $50 \mathrm{~mol} \%$ (the percentage of alternated sequence is ranging between 64 and 78\%, while that of the AN homosequences is ranging between 5 and 34\%). As expected, when the initial molar MATRIF composition increases, the homosequence of MATRIF units in the copolymer increases while the corresponding alternated heterosequences decreases, and therefore reduces the tendency to an alternated structure. It is also noted that the copolymer at 50/50 mol. feed ratio exhibits the higher tendency to an alternated structure. In fact, the hetero-dyads content $\left(\mathrm{M}_{\mathrm{MATRIF}}-\mathrm{M}_{\mathrm{AN}}\right)$ is close to $78 \%$, while the amount of $\left(\mathrm{M}_{\mathrm{AN}}-\mathrm{M}_{\mathrm{AN}}\right)$ and ( $\left.\mathrm{M}_{\mathrm{MATRIF}}-\mathrm{M}_{\mathrm{MATRIF}}\right)$ homo-dyads are equal to 5 and $17 \%$, respectively. This is attributed to the higher reactivity of MATRIF about AN thus forming homosequence as confirmed by the reactivity ratio.

Table 2 Structural data for the poly(AN-co-MATRIF) copolymers

\begin{tabular}{|c|c|c|c|c|c|}
\hline \multirow[b]{2}{*}{ Copolymer $^{\text {a) }}$} & \multicolumn{2}{|c|}{$\begin{array}{l}\text { Composition } \\
\text { in copolymer } \\
(\% \mathrm{~mol})\end{array}$} & \multicolumn{2}{|c|}{$\begin{array}{l}\text { Homosequences } \\
\quad(\mathrm{mol} \%)\end{array}$} & \multirow{2}{*}{$\begin{array}{l}\begin{array}{c}\text { Alternation } \\
(\mathrm{mol} \%)\end{array} \\
\mathrm{M}_{\mathrm{AN}}-\mathrm{M}_{\mathrm{MATRIF}}\end{array}$} \\
\hline & $\mathrm{F}_{\mathrm{AN}}$ & $\mathrm{F}_{\text {MATRIF }}$ & $\mathrm{M}_{\text {MATRIF- }} \mathrm{M}_{\text {MATRIF }}$ & $\mathrm{M}_{\mathrm{AN}}-\mathrm{M}_{\mathrm{AN}}$ & \\
\hline Poly(AN-co-MATRIF) 15/85 & 19 & 81 & 63 & 0 & 37 \\
\hline Poly(AN-co-MATRIF) 25/75 & 28 & 72 & 45 & 1 & 54 \\
\hline Poly(AN-co-MATRIF) 50/50 & 44 & 56 & 17 & 5 & 78 \\
\hline Poly(AN-co-MATRIF) 75/25 & 60 & 40 & 3 & 23 & 74 \\
\hline Poly(AN-co-MATRIF) 85/15 & 66 & 34 & 2 & 34 & 64 \\
\hline
\end{tabular}

The Pyn ${ }^{52}$ method is also useful to assess the mean sequence lengths, $\mu_{1}$ and $\mu_{2}$, of AN and MATRIF monomers, respectively, which can be calculated by the following equations:

$$
\begin{aligned}
& 1=1+r_{1} \frac{\left[M_{1}\right]}{\left[M_{2}\right]} \\
& 2=1+r_{2} \frac{\left[M_{2}\right]}{\left[M_{1}\right]}
\end{aligned}
$$


The mean sequence length distributions for the poly(AN-co-MATRIF) copolymers obtained by Pyun method are listed in Table 3.

According to the literature, if the probability of alternation, $\mathrm{p}\left(\mathrm{M}_{\mathrm{MATRIF}}-\mathrm{M}_{\mathrm{AN}}\right)$, is close to unity, a regular alternated sequence distribution is noted such as ...- $\mathrm{M}_{\mathrm{AN}}-\mathrm{M}_{\mathrm{MATRIF}}-\mathrm{M}_{\mathrm{AN}}-\mathrm{M}_{\text {MATRIF }}-\ldots$, and thus $\mu_{1}=\mu_{2}=1$. In the present study, all the $\mu_{1}$ and $\mu_{2}$ values are not equal to unity which predicts the formation of $\left(\mathrm{M}_{\mathrm{AN}}-\mathrm{M}_{\mathrm{AN}}\right)$ and ( $\left.\mathrm{M}_{\mathrm{MATRIF}}-\mathrm{M}_{\mathrm{MATRIF}}\right)$ homosequences. In fact, these values are closed to unity when the feed composition in AN increases (Table 3), as the $\mathrm{p}\left(\mathrm{M}_{\text {MATRIF }}-\mathrm{M}_{\mathrm{AN}}\right)$ is higher in comparison to that of the homosequences leading to tendency toward alternation. As expected, when the molar percentage of MATRIF in the feed increases from 72 to $81 \%$, the percentage of alternated dyads is lower than that of MATRIF homosequence in the copolymer (\% $\mathrm{M}_{\text {MATRIF }}-\mathrm{M}_{\mathrm{AN}}$ decreases from 54 to $37 \%$, Table 2), and therefore the sequence length of MATRIF increases, its value is greater than unity (ranging between 2.00 and 2.20, Table 3). These results are in good agreement with those obtained from the reactivity ratios.

Table 3 Length sequences of AN $\left(\mu_{1}\right)$ and MATRIF $\left(\mu_{2}\right)$ in poly(AN-co-MATRIF) copolymers

\begin{tabular}{ccc}
\hline & \multicolumn{2}{c}{ Mean sequence length } \\
\cline { 2 - 3 } Copolymer Name $^{\mathrm{a}}$ & $\mu_{1}$ & $\mu_{2}$ \\
\hline Poly(AN-co-MATRIF) 15/85 & 1.02 & 2.00 \\
Poly(AN-co-MATRIF) 25/75 & 1.03 & 2.20 \\
Poly(AN-co-MATRIF) 50/50 & 1.07 & 1.60 \\
Poly(AN-co-MATRIF) 75/25 & 1.15 & 1.27 \\
Poly(AN-co-MATRIF) 85/15 & 1.17 & 1.24 \\
\hline
\end{tabular}

${ }^{\text {a }}$ Poly(AN-co-MATRIF) $\mathrm{n} / \mathrm{m}$, where $\mathrm{n}$ and $\mathrm{m}$ stand for the molar percentages of AN and MATRIF in the feed, respectively

The calculated dyad fractions and sequence lengths do not take the composition drift into account, particularly in polymerizations containing a high AN amount. This drift is most affected by the different solubility of both comonomers in water. The possibility of a composition drift can be considered by checking the sequence distributions obtained from ${ }^{13} \mathrm{C}$ NMR spectra. Actually, the study on the tacticity by NMR spectroscopy can provide more detailed information on the copolymer microstructure. In fact, the comonomer sequence 
distribution, stereochemical configurations [meso (m) and racemic (r) configurations], and configurational sequences (dyads, triads, tetrads, etc...) contribute to NMR peak splittings and broadenings, and therefore make the spectra more complex. The specific zone of the ${ }^{13} \mathrm{C}$ NMR spectrum of poly(AN-co-MATRIF)15/85 copolymer has been expanded in the 171-179 ppm range to highlight the chemical shifts of the carbonyl group (Figure 3a). The carbonyl peaks are sensitive to the surroundings of both comonomers. Two peaks centered at 175.8 and $176.1 \mathrm{ppm}$ (in the range 175.5-176.4 ppm), and two other signals centered at 175.1 and 175.3 ppm (in the range 174.9-175.5 ppm) are observed and assigned to MATRIF homosequence triads and alternating sequence triads, respectively. Both low field peaks correspond to thermodynamical stable structures of PMATRIF homotriads ( $\mathrm{rr}$ and $\mathrm{rm}$ ) (Figure $3 \mathrm{~b}$ ) while the two other ones are assigned to alternated structures in the co-meso and co-racemic triads (Figure $3 b$ ). The ratio of areas of both sequences are in agreement with that calculated from the Igarashi's model (MATRIF-MATRIF-MATRIF/AN-MATRIF-AN=63/37).

To study the incorporation of AN comonomer in the poly(AN-co-MATRIF) copolymers on the thermal and dielectric properties, three copolymers were chosen by varying the initial $[\mathrm{AN}]_{0}:[\mathrm{MATRIF}]_{0}$ molar ratios between 25:75 and 75:20 (Entries E2-E4) and noted poly(ANco-MATRIF) 25:75, poly(AN-co-MATRIF) 50:50 and poly(AN-co-MATRIF) 75:25. 
(a)
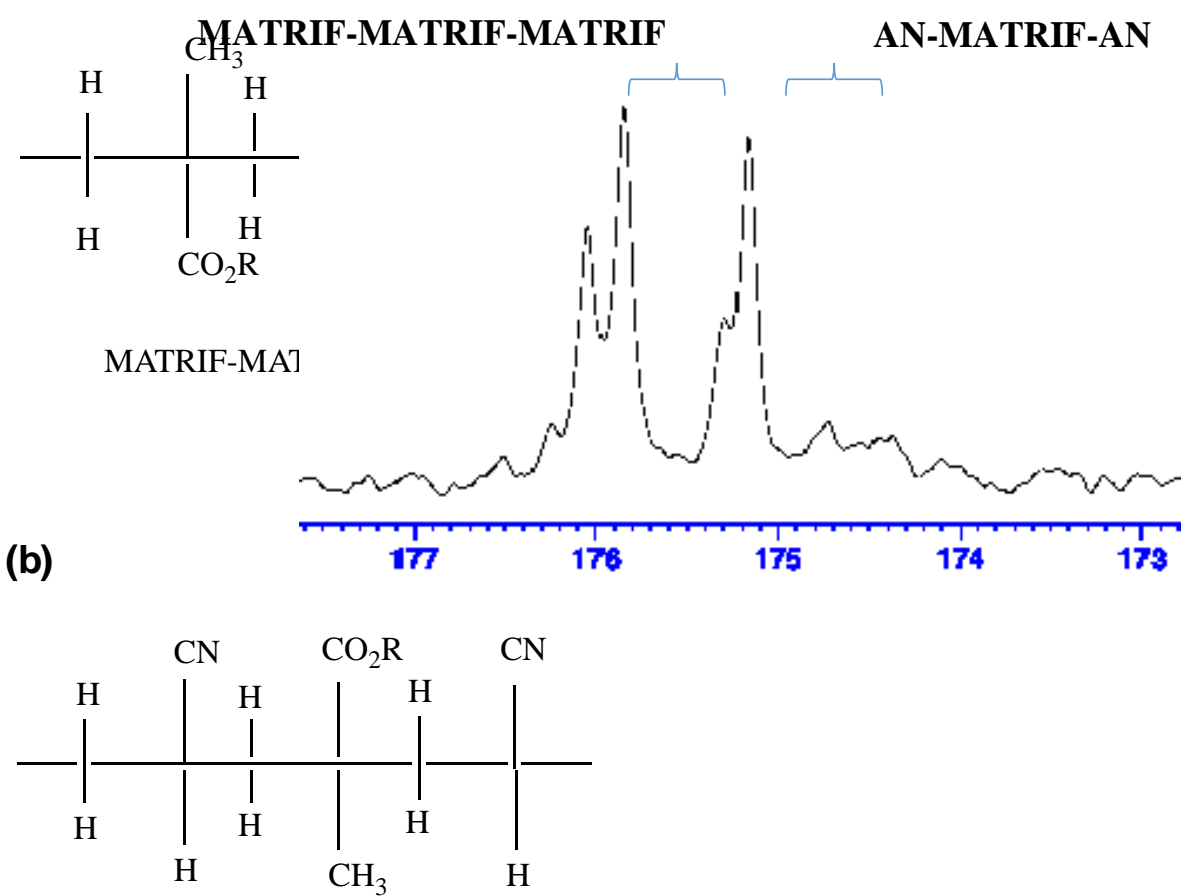

AN-MATRIF-AN Triad comeso (m)

Figure 3 Expanded carbonyl region of the ${ }^{13} \mathrm{C}$ NMR spectrum of poly(AN-coMATRIF)15/85 copolymer in the range 171-179 ppm (DMSO $\mathrm{d}_{6}$ ) (Top); Configuration of : Homosequence triads of MATRIF (middle), and alternating triads (Bottom) (where R stands for $\mathrm{CH}_{2} \mathrm{CF}_{3}$ ).

\subsection{Thermal properties}

The thermal properties of poly(AN-co-MATRIF) copolymers were studied by differential scanning calorimetry (DSC) as displayed in Figure 4.

The glass transition temperature, $\mathrm{T}_{\mathrm{g}}$, of poly(AN) is close to $94{ }^{\circ} \mathrm{C}$. This value was explained by the interaction of adjacent cyano groups which enhances the resistance of inner rotation of the main chain and decreases its flexibility. ${ }^{53}$ Compared to rigid poly(AN), poly(MATRIF) is more flexible by the presence of ester group $\left(\mathrm{OCH}_{2} \mathrm{CF}_{3}\right)$ in its side chain that increases the mobility of the main chain leading to lower $\mathrm{T}_{\mathrm{g}}\left(\mathrm{T}_{\mathrm{g}}=76^{\circ} \mathrm{C}\right.$, Table 4$)$ than that of poly(AN). In addition, the poly(AN-co-MATRIF) copolymers also exhibit low $\mathrm{T}_{\mathrm{g}}$ ranging between 75 and $\quad 78{ }^{\circ} \mathrm{C}$ as the mole percentage of $\mathrm{AN}$ increases from 18 to $66 \mathrm{~mol} \%$ in the copolymer (Table 4 5). These results are in good agreement with the microstructure and sterosequence distribution results obtained using Igarashi's method (Table 2 3). In fact, the presence in the copolymers of both flexible homo-dyads ( $\left.\mathrm{M}_{\text {MATRIF-M }} \mathrm{M}_{\text {MATRIF }}\right)$ and alternated hetero-dyads $\left(\mathrm{M}_{\text {MATRIF }}-\mathrm{M}_{\mathrm{AN}}\right.$ ), obtained by incorporation of MATRIF between AN units, reduces the strong intermolecular dipolar interactions between adjacent cyano groups and 
therefore reduces the $T_{g}$ of the resulting copolymers. It is also noted that such a value is not much affected by increasing the AN content in the copolymer (Table 4).

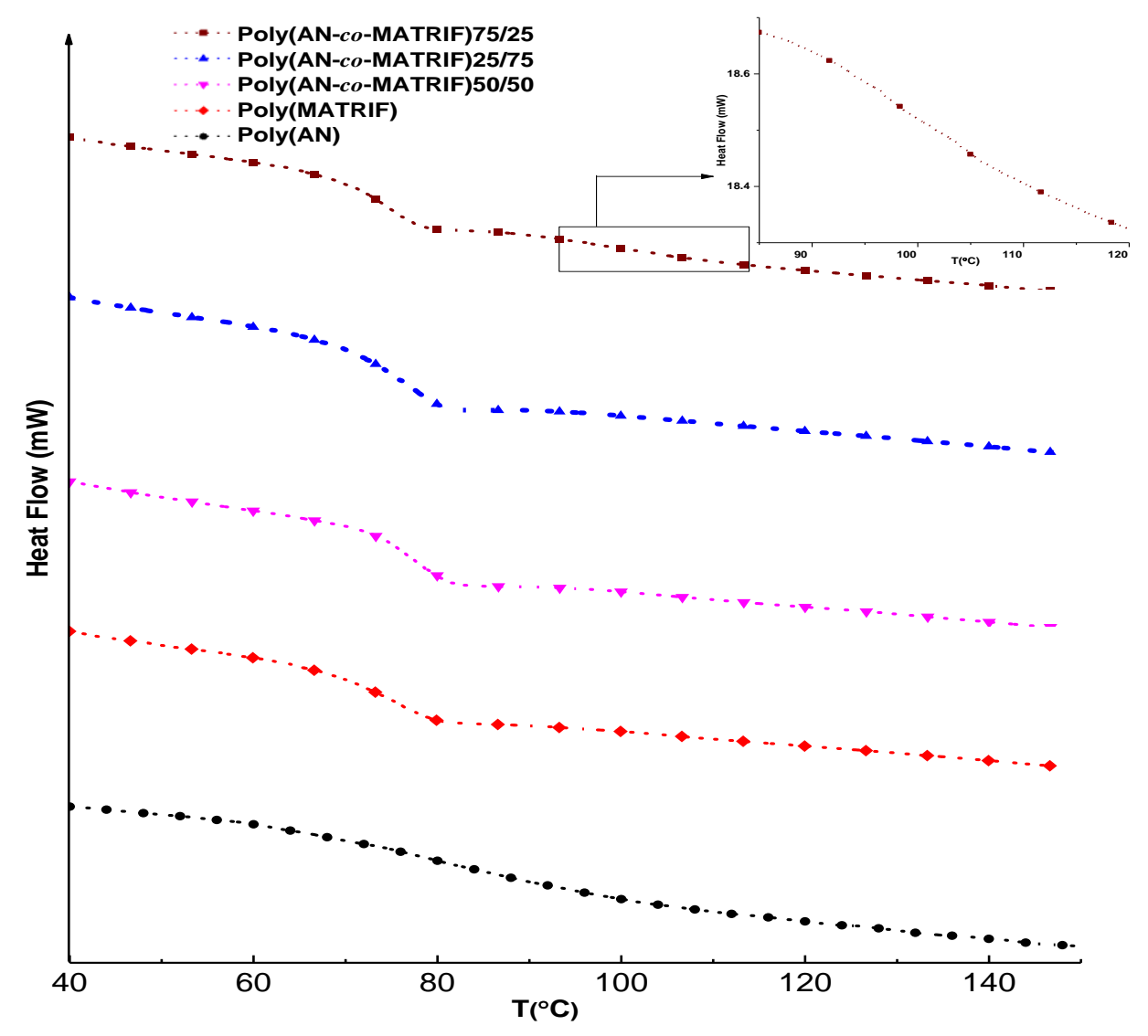

Figure 4 DSC thermograms of poly(AN-co-MATRIF) copolymers of various compositions and of the corresponding homopolymers

Table 4 Glass transition temperature of poly(AN-co-MATRIF) copolymers and homopolymers

\begin{tabular}{|c|c|c|c|}
\hline (Co)Polymer $\left.{ }^{a}\right)$ & $\begin{array}{l}\text { AN (mol. \%) } \\
\text { in copolymer }\end{array}$ & $\mathrm{T}_{\mathrm{g}}\left({ }^{\circ} \mathrm{C}\right){ }^{\mathrm{b})}$ & $\mathrm{T}_{\mathrm{g}}\left({ }^{\circ} \mathrm{C}\right)$ Fox ${ }^{\mathrm{c}}$ \\
\hline Poly(AN) & 100 & 94 & - \\
\hline Poly(MATRIF) & 0 & 76 & - \\
\hline Poly(AN-co-MATRIF) 25/75 & 28 & 78 & 92 \\
\hline Poly(AN-co-MATRIF) 50/50 & 44 & 76 & 90 \\
\hline Poly(AN-co-MATRIF) 75/25 & 60 & 75 & 88 \\
\hline
\end{tabular}




\footnotetext{
${ }^{\mathrm{c}}$ Theoretical values from Fox's law (Eq.4)
}

The DSC thermograms (Figure 4) of all the copolymers show a single glass transition temperature evidencing the absence of a mixture of homopolymers or the formation of a "block" copolymers. A similar result was observed in some copolymers prepared by bulk or solution (acetonitrile) radical copolymerization of cyano monomers (i.e. acrylonitrile, methacrylonitrile and vinylidene cyanide) with fluorinated (meth)acrylates such as MATRIF and 2,2,2-trifluoroethyl acrylate. ${ }^{34,36,54}$

Usually, the dependence of $\mathrm{T}_{\mathrm{g}}$ value on the copolymer composition can be evaluated by the well-known Fox equation (Eq. 4): ${ }^{-55}$

$$
\frac{1}{T_{g}}=\frac{w_{1}}{T_{g 1}}+\frac{w_{2}}{T_{g 2}}
$$

where $\mathrm{w}_{1}$ and $\mathrm{w}_{2}$ are the massic percentages of AN and MATRIF, respectively, while $\mathrm{T}_{\mathrm{g} 1}$ and $\mathrm{T}_{\mathrm{g} 2}$ stand for the glass transition temperatures of poly(AN) and poly(MATRIF), respectively. The theoretical values are summarized in Table 4. $\mathrm{T}_{\mathrm{g}}$ of poly(AN-co-MATRIF) copolymers cannot be regressed well with Fox equation especially with the AN molar percentage above $40 \%$ which may be due to a high concentration of alternating sequences in the copolymers (i.e. $\% \mathrm{M}_{\mathrm{MATRIF}}-\mathrm{M}_{\mathrm{AN}}$ in poly(AN-co-MATRIF) copolymers decreases from 78 to $74 \%$ when the molar \% AN increases from 44 to $60 \%$, respectively). ${ }^{56}$ Similar results were reported by $\mathrm{Xu}$ et al. ${ }^{30}$ for a series of copolymers of MATRIF and methyl acrylate of different copolymer compositions.

It is worth noting that a wide second transition appears at higher temperature $\left(\mathrm{ca} .105^{\circ} \mathrm{C}\right)$ in the case of poly(AN-co-MATRIF) 75/25 (Figure 4). This could be attributed to the presence of AN homosequences that relax at higher temperature (in the $90-120{ }^{\circ} \mathrm{C}$ range). ${ }^{40}$

Generally, DSC does not well detect the presence of sequences in the copolymers. For this reason, that thermal study was completed by dynamic mechanical analysis (DMA) as sensitive tool for the detection of different molecular relaxations, therefore bringing deeper insights on the polymer microstructure. It is also used to detect sub-transition such as $\beta$ relaxation (local movement of polymer groups). Actually, regarding $\mathrm{T}_{\mathrm{g}}$ detection, both DSC and DMA techniques are responsive to similar molecular relaxation occurring over different domain sizes $L$ (in $\mathrm{nm}$ ) (i.e. $L \approx 15 \mathrm{~nm}$ in DMA and $L \approx 25 \mathrm{~nm}$ for DSC). ${ }^{-57-59}$

\subsection{Dynamic mechanical analysis (DMA)}


Figure 5 shows the evolution of the loss factor, $\tan \delta$, as a function of temperature.

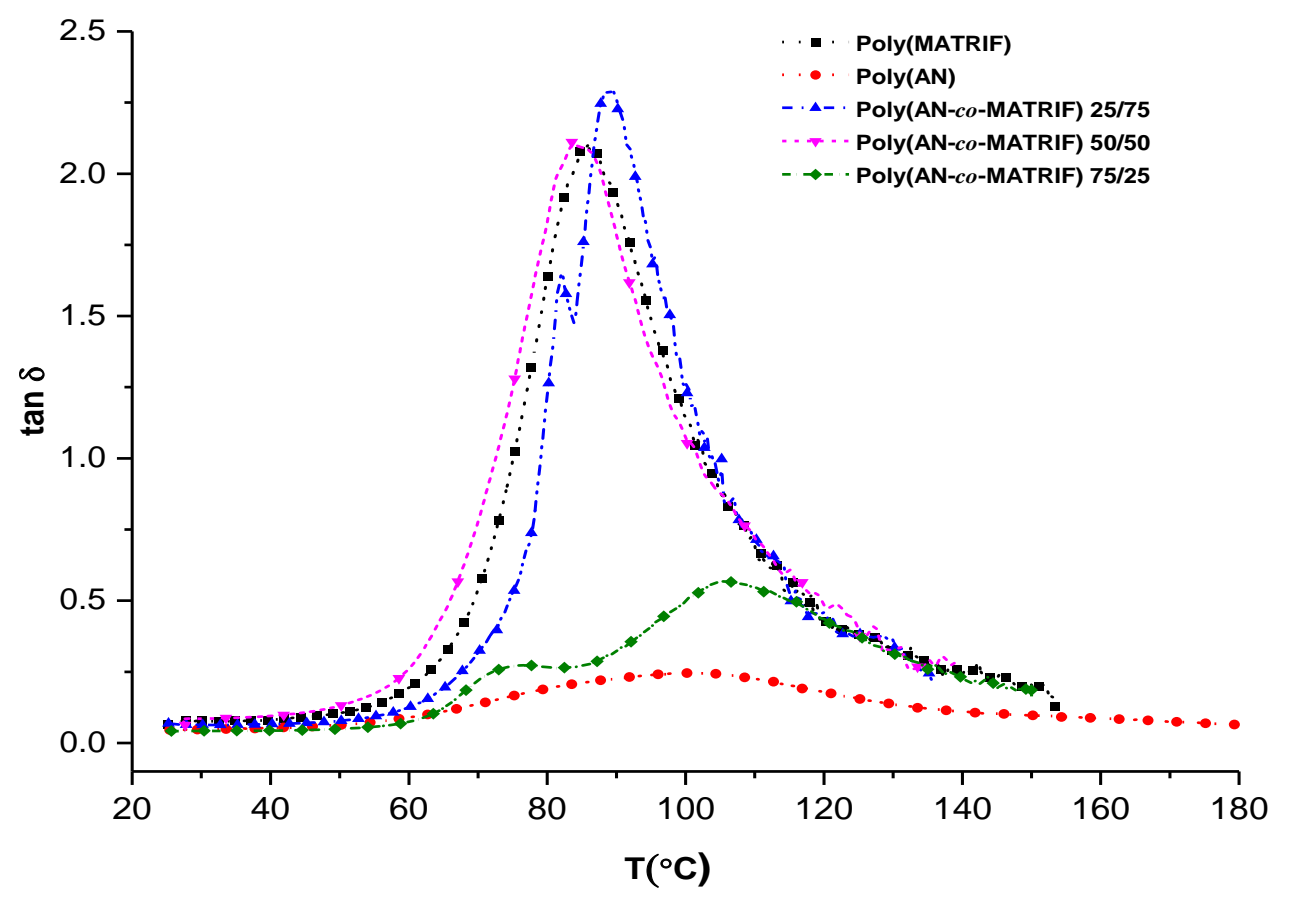

Figure 5 Evolution of $\tan \delta$ versus of temperature of poly(AN-co-MATRIF) copolymers and homopolymers at $1 \mathrm{Khz}$

The DMA thermograms of all (co)polymers display a peak in the range of the glass transition temperature (Tg) except in the case of poly(AN-co-MATRIF) 25/75 and poly(AN-coMATRIF) 75/25 where a second relaxation is noted. Compared to DMA curves of poly(AN) and poly(MATRIF), the first relaxation in the poly(AN-co-MATRIF) 25/75 copolymer and the second braod signal in the poly(AN-co-MATRIF) 75/25 copolymer could be attributed to the local relaxation corresponding to $\left(\mathrm{M}_{\mathrm{MATRIF}}-\mathrm{M}_{\mathrm{MATRIF}}\right)$ and $\left(\mathrm{M}_{\mathrm{AN}}-\mathrm{M}_{\mathrm{AN}}\right)$ homosequences, respectively. The DMA results are in good agreement with the calculated homosequenses determined from Igarashi's method, which are close to $45 \mathrm{~mol} \%$ for MATRIF homosequences and $23 \mathrm{~mol} \%$ for AN homo-dyades in poly(AN-co-MATRIF) 25/75 and poly(AN-co-MATRIF) 75/25 copolymers, respectively (Table 3).

Thus, DMA analyses complete the DSC measurements and confirm the presence of homosequences in these copolymers. This approves the validity of the models used for the prediction of microstructure and stereosequence distribution (Igarashi theory and Pyun method) described above.

\subsection{Dielectric properties}




\subsubsection{Dynamics of poly(MATRIF) homopolymer}

The molecular dynamic (i.e. segmental and chain mobilities) of poly(AN-co-MATRIF) copolymers with different compositions are explored by broadband dielectric spectroscopy as a function of temperature, and compared with those of poly(MATRIF) homopolymer as a reference, to highlight the significant changes introduced by the incorporation of the rigid and polar AN comonomer.

The relaxation behavior of poly(MATRIF) is shown in Figure 6 in which selected spectra of isochronal scan at various frequencies $v=20 \mathrm{~Hz}, 100 \mathrm{~Hz}, 1 \mathrm{kHz}$ and $1 \mathrm{MHz}$ of the dielectric permittivity, $\varepsilon^{\prime}$, and dissipation factor, $\tan \delta$, as function of temperature were reported.
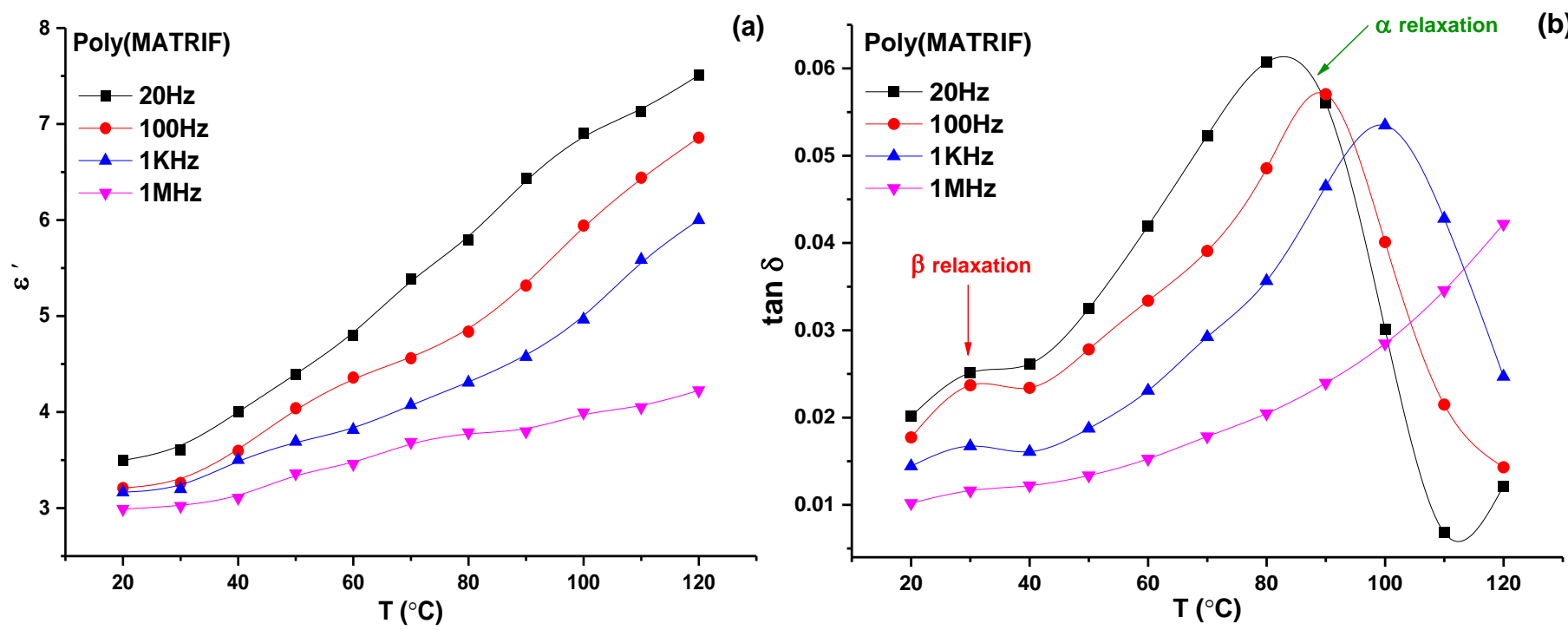

Figure 6 Selected isochronal spectra of poly(MATRIF) homopolymer as function of temperature: (a) dielectric permittivity ( $\left.\varepsilon^{\prime}\right)$; dissipation factor $(\tan \delta): \alpha$ and $\beta$ relaxations.

Poly(MATRIF) exhibits a dynamic scenario with two relaxation processes, similar to that shown in non-fluorinated analogous poly(ethyl methacrylate) ${ }^{60} \quad$ At $\mathrm{T}<\mathrm{T}_{\mathrm{g}}$ ( $\mathrm{T}$ is ranging between 20 and $40{ }^{\circ} \mathrm{C}$ ), dielectric permittivity, $\varepsilon^{\prime}$, is lower and practically independent of frequency in the glassy state is observed $\left(3<\varepsilon^{\prime}<3.5\right)$. In addition, a secondary relaxation, $\beta$, is detectable even at low frequencies (Figure 5b). This $\beta$-relaxation time of glassy poly(MATRIF) is rather similar as those reported for poly(EMA) based on dynamic mechanical ${ }^{60}$ as well as dielectric relaxation experiments. ${ }^{61,62}$ This process is probably due to a $180^{\circ}$ flip rotation of the carboxy ester side group coupled to a restricted rocking motion of a directly connected main chain segmental unit, as demonstrated by Spiess for poly(methyl methacrylate), PMMA and poly(EMA) ${ }^{63,64}$ and poly(fluoroalkyl $\alpha$-substituted acrylate)s. ${ }^{65}$ At high temperatures $\left(T>T_{\mathrm{g}}\right)$ and low frequencies, the primary relaxation process, $\alpha$, related 
to the calorimetric glass transition, is active, and is responsible for the main step observed in the real part of permittivity. The $\alpha$-relaxation is usually ascribed to the structural process, and thus associated with the glass transition phenomenon, arising from the cooperative motions of several segments of the same or adjacent chains. This result is in good agreement with the data reported in the literature. ${ }^{35,38}$ Electrode polarization is negligible, as evidenced by the low values of $\varepsilon 2$ at $\mathrm{T}>\mathrm{T}_{\mathrm{g}}$.

\subsubsection{Dynamics of poly(AN-co-MATRIF) copolymers}

Introduction of polar cyano groups as a result of copolymerization of MATRIF with AN from different initial $[\mathrm{AN}]_{0}:[\mathrm{MATRIF}]_{0}$ ratios induces effects on both the dynamic properties and the absolute permittivity value $\left(\varepsilon^{\prime}\right)$. Isochronal scans recorded on poly(AN-co-MATRIF) copolymers with different compositions at various frequencies $(v=20 \mathrm{~Hz}, 100 \mathrm{~Hz}, 1 \mathrm{kHz}$ and $1 \mathrm{MHz}$ ) revealed the presence of several processes, as shown in the dielectric permittivity $\left(\varepsilon^{\prime}\right)$ and dissipation factor $(\tan \delta)$ plots (Figure 7). For the poly(AN-co-MATRIF) copolymers, both $\varepsilon^{\prime}$ and $\tan \delta$ are higher than those of the reference poly(MATRIF) homopolymer (Figure 6).

Figure 7a shows that in the glassy state (below $\mathrm{T}_{\mathrm{g}}$ ), the dipolar orientation is mainly blocked. The dielectric constant values of different poly(AN-co-MATRIF) copolymers are low, almost independent of both the temperature and frequency, and dominated by the high frequency permittivity $\left(\varepsilon_{\infty}{ }_{\infty}\right)$ that is a quite typical value for the atomic and electronic polarization. ${ }^{63} \varepsilon_{\infty}$ values for poly(AN-co-MATRIF) copolymers, 50/50 and 75/25 were 4 and 5, respectively. These values are slightly higher than that of poly(MATRIF) homopolymer $\left(\varepsilon^{\prime}=3.2\right)$ due to the incorporation of polar AN units. Indeed, $\varepsilon_{\infty}^{\prime}$ values of the copolymers increase with the molar AN incorporation in the resulting copolymers.

At $\mathrm{T}>70{ }^{\circ} \mathrm{C}$ (around $\mathrm{T}_{\mathrm{g}}$ ), the dielectric permittivity increases significantly with increasing temperature and lowering the frequencies, due to the increase in segmental motions of dipoles units (Figure 7). In fact, above $\mathrm{T}_{\mathrm{g}}$, the molecular dipoles and especially polar cyano ($\mathrm{CN})$ groups of $\mathrm{AN}$ units are able to orient under the external field. Therefore, the molecular dynamic features can be described by an important parameter, called dielectric increment or total static dielectric polarization, $\Delta \varepsilon$, which can be obtained as the difference between the static permittivity $\left(\varepsilon_{\mathrm{s}}\right)$ and the high frequency permittivity $\left(\varepsilon_{\infty}\right)$. This dielectric increment of the poly(AN-co-MATRIF) copolymers is more important as the AN fraction increases in the copolymer. 

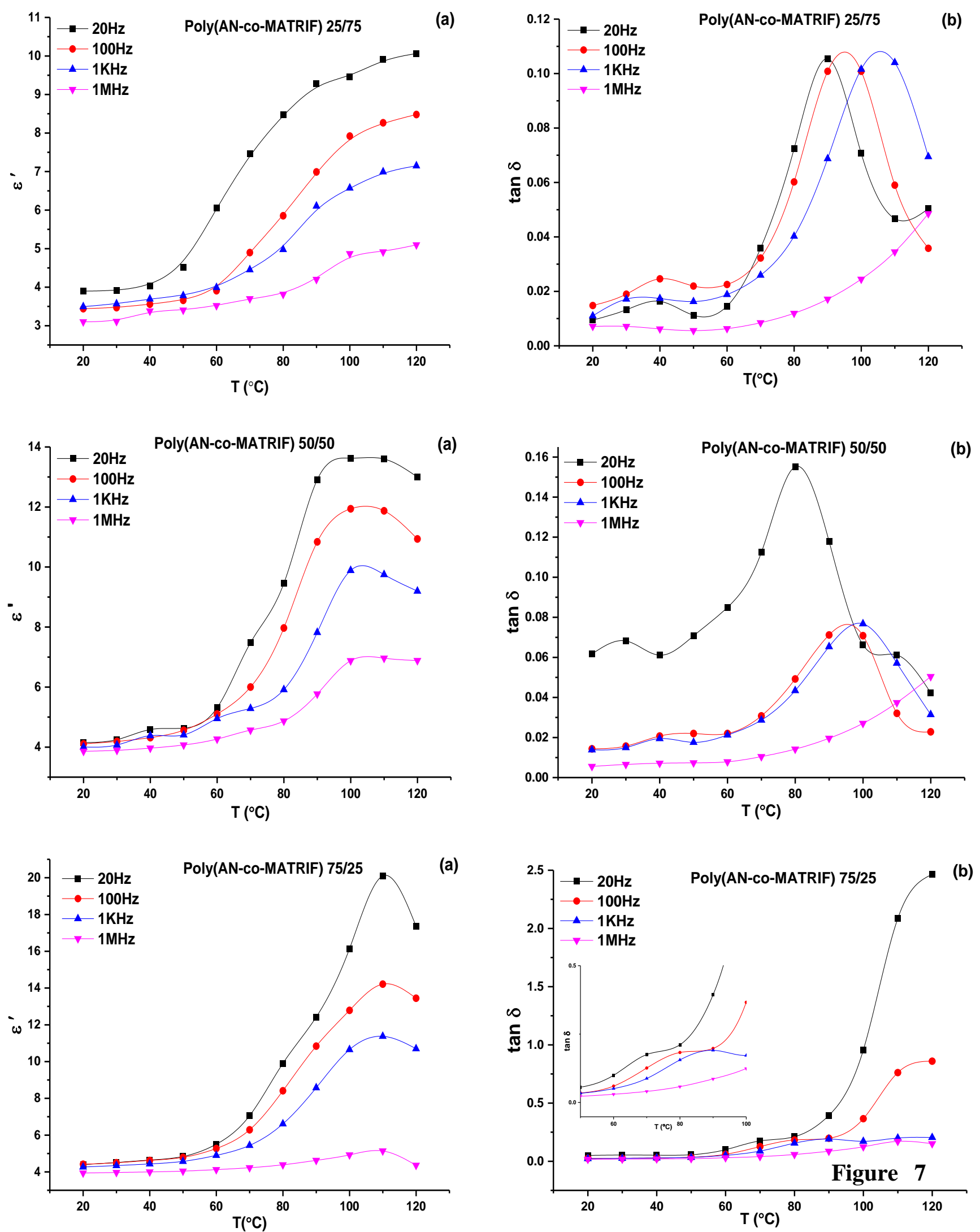

Selected isochronal spectra of poly(AN-co-MATRIF) copolymers of different compositions versus the temperature : (a) dielectric permittivity $\left(\varepsilon^{\prime}\right)$; (b) dissipation factor $(\tan \delta)$ 
The variation of dissipation factor, $\tan \delta$, versus the temperature at different frequencies is presented in Figure $7 \mathrm{~b}$ and evidences the existence of two relaxations. In the glass transition temperature domain, a relaxation phenomena assigned to $\alpha$ relaxation is observed for all poly(AN-co-MATRIF) copolymers. This relaxation is related to the cooperative reoriontation motion of wide segments containing the backbone (polar dipole $\mathrm{CN}$ of $\mathrm{AN}$ units), above $\mathrm{T}_{\mathrm{g}}$ as suggested by Furukawa et al. ${ }^{67}$ Similar results were reported in previous works related to the dielectric study of copolymers based on cyano monomers and fluorinated (meth)acrylate. 31, 34 The maximum of each peak is shifted to higher frequencies as the temperature increases due to an enhancement of dipolar mobility in the origin of cooperative motions above $\mathrm{T}_{\mathrm{g}}$. Below $\mathrm{T}_{\mathrm{g}}\left(30<\mathrm{T}<40{ }^{\circ} \mathrm{C}\right)$, a weak secondary relaxation, $\beta$, was also noted in the dielectric spectra of poly(AN-co-MATRIF) copolymers (Figure 7b), and similar to that observed in the dielectric spectra of poly(MATRIF) homopolymer (Figure 6). The $\beta$ relaxation can be attributed to a rotational motion of carboxy ester groups of MATRIF units in the glassy region also involving restricted motions of the main chain ${ }^{63}$ and an internal motion of fluoroalkyl side chains, respectively. In fact, dipolar fluctuations associated with conformational motions involving the stiffening of cyano groups are negligible in the glassy state, while those associated to vibrational modes are not relevant since they take place over a much faster time scale, as already demonstrated by previous studies on poly(vinylidene cyanide-co-vinyl ester) copolymers. ${ }^{68,69}$ On the other hand, the cyano groups do not significantly affect the nature of the low temperature $\beta$ relaxation.

In addition, the effect of the incorporation of polar group $\mathrm{CN}$ with different proportions on dielectric properties of poly(MATRIF) was studied. Figure 8 shows a comparison of dielectric permittivities and dielectric dissipation factors of poly(AN) and poly(MATRIF) homopolymers and poly(AN-co-MATRIF) copolymers versus temperature at $1 \mathrm{Khz}$.

Figure $8 \mathrm{a}$ indicates that the dielectric permittivity values, $\varepsilon$, of copolymers above $\mathrm{T}_{\mathrm{g}}$ are higher comparatively to that of poly(MATRIF) homopolymer. The increases of $\varepsilon$ ' arises from the introduction of polar AN comonomer which has a high dipole moment. For example, the dielectric constant value of poly(AN-co-MATRIF) 75/25 is 11 while that of poly(MATRIF) is 6 (at $120^{\circ} \mathrm{C}$ and at $1 \mathrm{Khz}$ ). This value is higher than those of polar polymers, usually ranging between 2 and 5 , excepted for fluorinated polymers. ${ }^{70}$ 


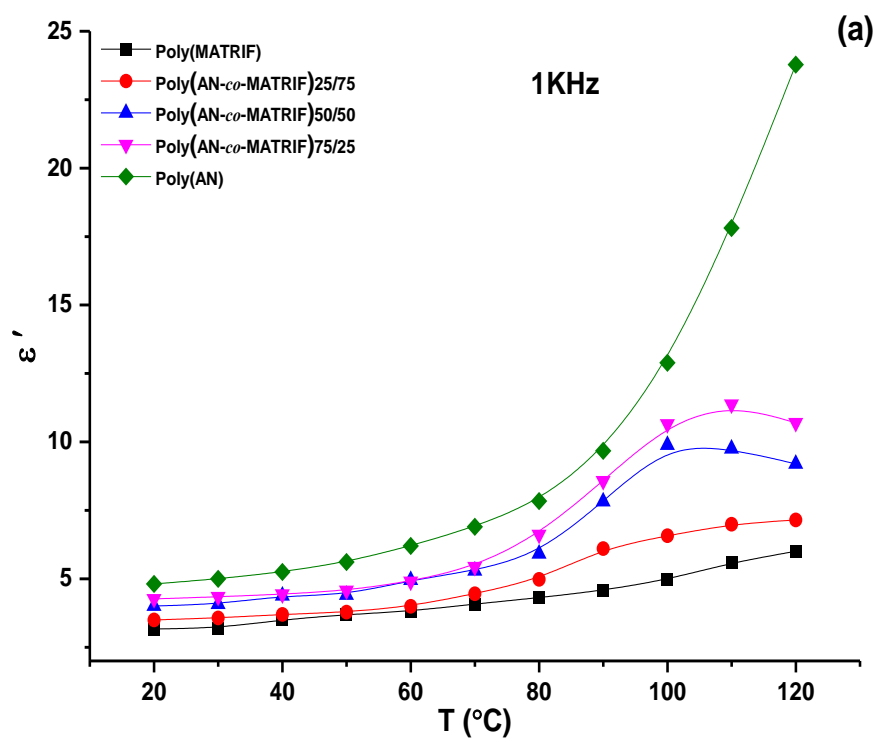

(a)

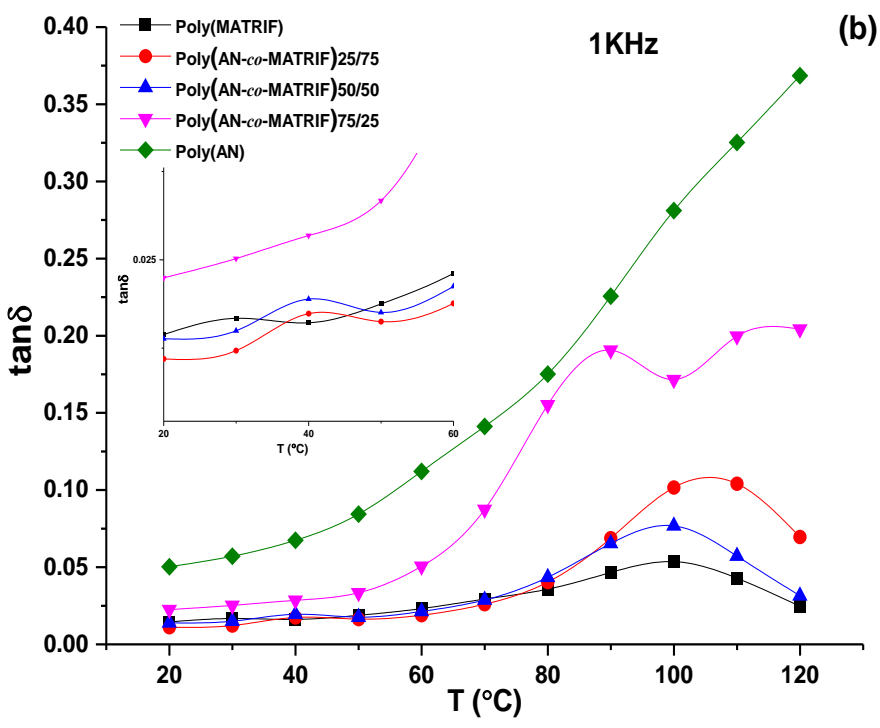

Figure 8 Dielectric spectra of the variation of dielectric permittivity $\left(\varepsilon^{\prime}\right)$ and dielectric dissipation factor $(\tan \delta)$ versus the temperature of homopolymers and copolymers at $1 \mathrm{Khz}$

Figure $8 \mathrm{~b}$ exhibits the dielectric dissipation factor and evidences that the intensity of $\beta$ relaxation of copolymers decreases when the proportion of $\mathrm{CN}$ groups increases. It is also observed that the maximum of the peak of such secondary relaxation in poly(AN-coMATRIF) 25/75 and poly(AN-co-MATRIF) 50/50 shifts to higher temperatures than that of poly(MATRIF). This result can be attributed to the presence of rigid $\mathrm{CN}$ groups which prevent from the rotation of $\mathrm{CO}_{2} \mathrm{CH}_{2} \mathrm{CF}_{3}$ lateral groups responsible for this relaxation. Indeed, the motion of such bulky side-groups in $\mathrm{M}_{\text {MATRIF-M }} \mathrm{M}_{\text {MATRIF }}$ homosequences is easier that in the case of alternating sequences, $\mathrm{M}_{\mathrm{AN}}-\mathrm{M}_{\mathrm{MATRIF}}$, where two rigid $\mathrm{CN}$ groups surround a MATRIF unit, inducing a steric hindrance, which avoids their motion, and consequently their relaxations. The disappearance of the $\beta$ relaxation is observed in the case of poly(AN-coMATRIF) 75/25.

Figure $8 \mathrm{~b}$ displays the presence of the primary relaxation $\alpha$ in all copolymers and poly(MATRIF), except in the case of poly (AN). In addition, the observed shift towards higher temperatures in the poly(AN-co-MATRIF) copolymers, compared to poly(MATRIF) means that the molecular dynamics associated with the glass transition, becomes more hindered in the copolymer. The slowness of this cooperative motion arises from the substitution of part of the bulky $\mathrm{CO}_{2} \mathrm{CH}_{2} \mathrm{CF}_{3}$ side groups by the more rigid $\mathrm{CN}$ groups, which increases the stiffness of the polymer main-chain.

The molecular dynamic features can also be described by an important parameter called dielectric increment or total static dielectric polarization, $\Delta \varepsilon$, that can be obtained as the 
difference between the static permittivity $\left(\varepsilon_{\mathrm{S}}\right)$ and the high frequency permittivity $\left(\varepsilon_{\infty}\right)$ associated with the various relaxation processes. According to the Onsager's theory ${ }^{71}$ the dielectric increment, $\Delta \varepsilon$, is proportional to the effective number of dipoles aligned with the external applied field (Eq. 5).

$$
\Delta \varepsilon_{T}=\varepsilon_{S}-\varepsilon_{\infty}=\sum_{i} \Delta \varepsilon_{i}=\frac{g_{k}}{k T} \cdot \sum_{j} N_{j} \mu_{j}^{2} \quad \text { (Eq. 5) }
$$

where $\mu \mathrm{j}, \Sigma \mathrm{jNj}$ and $\mathrm{g}_{\mathrm{k}}$ stand for the dipole moment associated to the molecular group $\mathrm{j}$, the total volume concentration of molecular dipoles, and the Kirkwood factor that takes into account the relative molecular orientation, respectively. ${ }^{72}$

The influence of the $\alpha$-relaxation process on the $\varepsilon$ ' value taking into consideration the dielectric strength $\Delta \varepsilon$ was examined. We have chosen to calculate $\Delta \varepsilon$ at a temperature corresponding to the maximum of the $\alpha$-relaxation of each polymer as the difference between $\varepsilon$ ' values at lower and higher temperatures, below and above $\mathrm{T}_{\mathrm{g}}$, respectively (Figure 8a). The obtained $\Delta \varepsilon$ values were 2.1, 8.0, 13.8 and 15.5 for poly(MATRIF), poly(AN-co-MATRIF) 25/75, poly(AN-co-MATRIF) 50/50 and poly(AN-co-MATRIF) 75/25, respectively. Figure 9 exhibits the evolution of $\Delta \varepsilon$ versus the $\mathrm{AN}$ content in the poly(AN-co-MATRIF) $\mathrm{x} / \mathrm{y}$

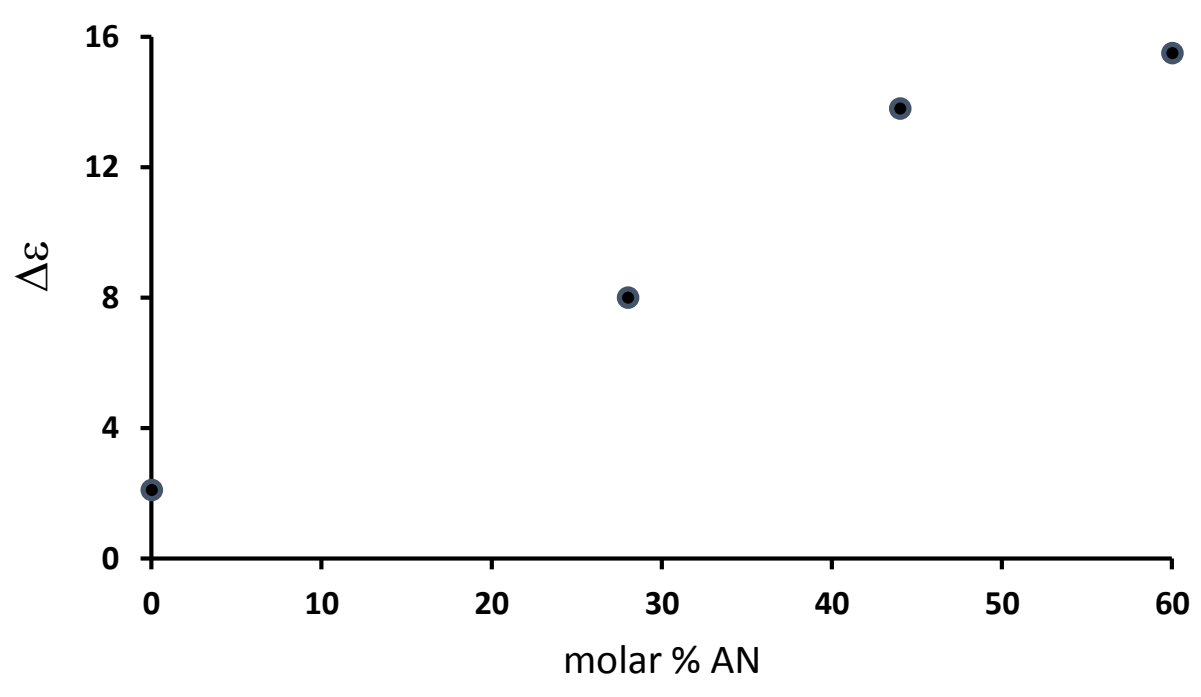

copolymers.

Figure 9 Evolution of $\Delta \varepsilon$ versus the molar composition of AN in the poly(AN-co-MATRIF) copolymers 
The dielectric increment value, $\Delta \varepsilon$, appears relatively low in poly(MATRIF) homopolymer ( $\Delta \varepsilon=2.1$ ), attributed to the small molecular dipole moment $\mu=1.34 \mathrm{D}$ calculated for the trifluoroethoxycarbonyl moiety of poly(MATRIF) according to the Onsager's theory (Eq.4). ${ }^{20}$ In addition, $\Delta \varepsilon$ values for poly(AN-co-MATRIF) copolymers are higher than that of the reference poly(MATRIF) homopolymer, reflecting the effect of the polarity due to the introduction of cyano dipoles of AN units. The high value of the dipole moment, $4 \mathrm{D}$, in several aliphatic compounds, ${ }^{73,74}$ explains the higher value in the dielectric strength in the copolymer. Indeed, as the concentration of the $\mathrm{CN}$ dipoles in the copolymer increases (Table 1), $\Delta \varepsilon$ value increases too. In fact, the dielectric strength value is proportional to the effective number of dipoles aligned with the applied electric field. ${ }^{69}$

\subsubsection{Dielectric breakdown}

The breakdown strength $\left(E_{b}\right)$ has a significant effect on the energy storage, it is also a main parameter for the dielectric properties of polymers and composites. Generally, such a feature has been analyzed by the two-parameter Weibull distribution function (Eq. 6).

$$
P(E)=1 \quad \exp \left\{\left(\frac{E}{E_{b}}\right)\right\}(\text { Eq. 6) }
$$

where $\mathrm{P}$ and $\mathrm{E}$ represent the cumulative probability of failure and the experimental breakdown strength, respectively. The characteristic breakdown strength $\left(\mathrm{E}_{\mathrm{b}}\right)$ was obtained when the cumulative probability of electrical failure (P) worthes $63.2 \%$ and $\beta$ is the shape parameter calculated through linear fitting that evaluates the data distribution. ${ }^{75-78}$

Figure 10 exhibits the Weibull distribution of $\mathrm{E}_{\mathrm{b}}$ of the homopolymers and copolymers, the corresponding values being summarized in Table 5.

As the values of dielectric breakdown, $\mathrm{E}_{\mathrm{b}}$, are linked to the thickness of the films, ${ }^{79}$ the measurements of $E_{b}$ have been performed on samples that exhibit the same thickness. The $E_{b}$ values determined for different copolymers were influenced by their structure (the molar fraction of MATRIF into the copolymer), and were higher than that of poly(AN) (Table 5 ) and polar homopolymers where the $\mathrm{E}_{\mathrm{b}}$ values are ranging between 24 and $300 .{ }^{70}$ Indeed, the poly(AN-co-MATRIF) 75/25 presents the highest $\mathrm{E}_{\mathrm{b}}$ value. In fact, the introduction of MATRIF comonomer bearing fluorinated groups into poly(AN) units suppresses the electron 
acceleration due to an increase of the scattering of conduction electrons. Thus, this leads to an increase of $\mathrm{E}_{\mathrm{b}}$ determined by the electron avalanche breakdown. Similar results were previously

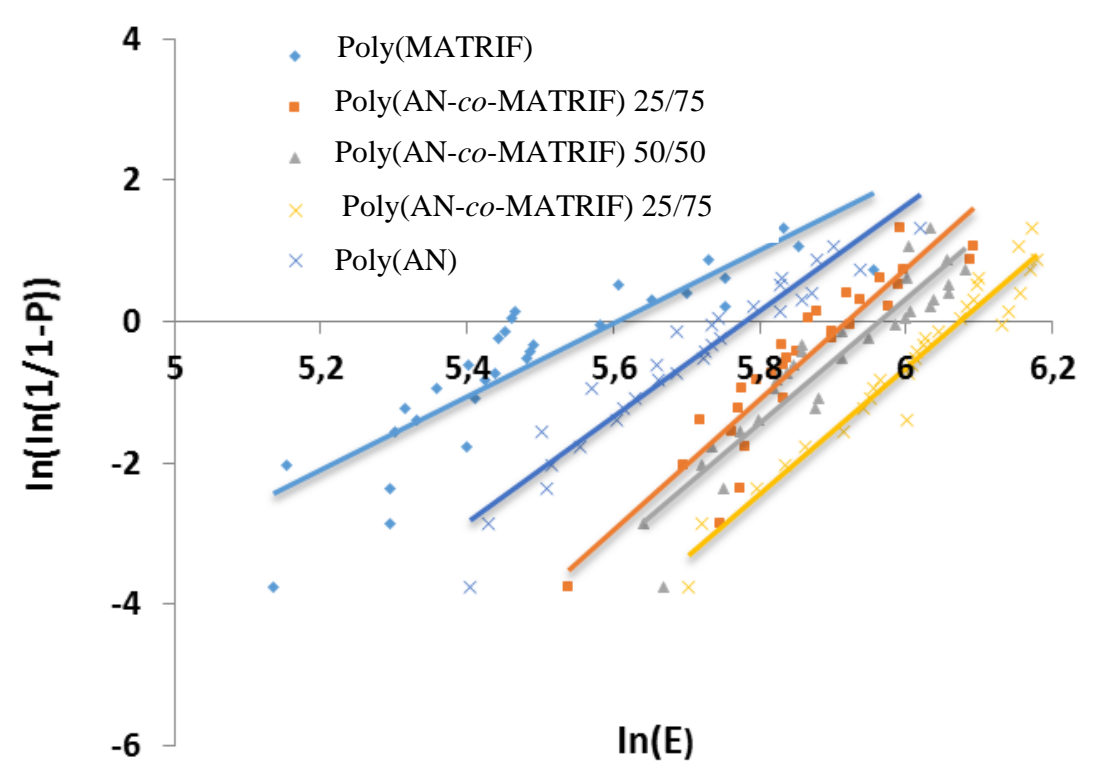

Figure 10 Distribution of Weibull of different AN and MATRIF containing (co)polymers.

Table 5 Dielectric breakdown $\left(E_{b}\right)$ and shape parameter $(\beta)$ of different polymer films at room temperature

\begin{tabular}{|l|c|c|c|c|}
\hline \multicolumn{1}{|c|}{$(\mathrm{Co})$ Polymer } & $\begin{array}{c}\text { Mol. \% } \\
\text { of MATRIF in } \\
\text { copolymers }\end{array}$ & $\begin{array}{c}\text { Thickness } \\
(\mu \mathrm{m})\end{array}$ & $\begin{array}{c}\mathrm{E}_{\mathrm{b}} \\
(\mathrm{MV} / \mathrm{m})\end{array}$ & $\beta$ \\
\hline Poly(AN) & - & $34 \pm 2$ & 324 & 8 \\
\hline Poly(AN-co-MATRIF) 75/25 & 28 & $34 \pm 2$ & 434 & 9 \\
\hline Poly(AN-co-MATRIF) 50/50 & 44 & $32 \pm 3$ & 390 & 9 \\
\hline Poly(AN-co-MATRIF) 25/75 & 60 & $36 \pm 3$ & 372 & 9 \\
\hline Poly(MATRIF) & - & $32 \pm 3$ & 272 & 6 \\
\hline
\end{tabular}

reported on the electrical breakdown of ethylene copolymers with halogenated comonomers such as MATRIF and 2,4,6-tribromobenzyl methacrylate. ${ }^{80,81}$ It is also noted that $\mathrm{E}_{\mathrm{b}}$ values 
decreased when the molar content of MATRIF increased (Table 6). A tentative explanation may be the presence of the high fluorine content in the amorphous AN chain gives rise to some kind of defects, thus leading to an $\mathrm{E}_{\mathrm{b}}$ decrease. ${ }^{80,81}$ In conclusion, compared to poly(AN) and poly(MATIF) homopolymers, the introduction of polar cyano groups in the MATRIF units via emulsion radical copolymerization of AN and MATRIF leads to an increase of both the dielectric strength $(\Delta \varepsilon)$ (Figure 9) and dielectric breakdown $\left(\mathrm{E}_{\mathrm{b}}\right)$ (Table 5), therefore increasing the energy density $\left(U_{e}\right)$ since it is proportional to both these parameters: $\mathrm{U}_{\mathrm{e}}=1 / 2 \varepsilon_{0} \varepsilon_{\mathrm{r}} \mathrm{E}_{\mathrm{b}}^{2}$.

\section{Conclusion}

The radical emulsion polymerization of AN with MATRIF was successful achieved and the resulting copolymers were suitable candidates as new electroactive amorphous materials with high dielectric permittivity, high dielectric breakdown and low dissipation factor. These poly(AN-co-MATRIF) copolymers were characterized by ${ }^{1} \mathrm{H},{ }^{13} \mathrm{C} \quad \mathrm{NMR}$ and IR spectroscopies, DSC, DMA and dielectric spectroscopy. Their compositions were determined by ${ }^{1} \mathrm{H}$ NMR spectroscopy. The kinetics of such a copolymerization using various initial $[\mathrm{AN}]_{0}:[\mathrm{MATRIF}]_{0}$ feed ratios enabled us to assess the reactivity ratios using the Extended Kelen-Tüdos method $\left(\mathrm{r}_{\mathrm{AN}}=0.09\right.$ and $=\mathrm{r}_{\mathrm{MATRIF}}=0.47$ at $\left.75^{\circ} \mathrm{C}\right)$. The $\mathrm{r}_{\mathrm{AN}} \times \mathrm{r}_{\text {MATRIF }}$ product being close to zero indicates that such copolymers exhibit a tendency to alternance with homosequences that is in good agreement with the study of the microstructure and stereosequence distribution from the Igarashi's and Pyun's models. These poly(AN-coMATRIF) copolymers exhibited $\mathrm{T}_{\mathrm{g}} \mathrm{s}$ in the $75-78{ }^{\circ} \mathrm{C}$ range depending on their compositions and they decreased with increasing MATRIF contents in the copolymer. The dielectric properties of these polymer films showed that the dielectric permittivity was improved with increasing the acrylonitrile molar content. Actually, $\Delta \varepsilon$ (poly(AN-co-MATRIF) $75 / 25)=15.5$ is seven times higher than that of poly(MATRIF) (2.1). The structure of these copolymers dielectric permittivity relationship was established and an improvement of dielectric breakdown $\left(\mathrm{E}_{\mathrm{b}}\right)$ was also observed.

This article not only describes a promising strategy for preparing high molar mass-poly(ANco-MATRIF) copolymers by tailoring their molar compositions, but also provides insights into the understanding of the structure-dielectric properties relationship and the energy storage capability. In addition, these results also strongly suggest that superior dielectric properties make the poly(AN-co-MATRIF) copolymers even at high AN composition as 
candidates for some applications amongst advanced electrical materials such as amorphous dielectric polymer layers for energy capacitor devices. Finally, measuring the dielectric relaxation strength is a practical way to evaluate the potential piezoelectricity of an amorphous polymer. ${ }^{82}$ On the other hand, enhancing the dielectric relaxation strength of poly(AN-co-MATRIF) 75/25 copolymer and hence its piezoelectric response must feature a high concentration of highly $\mathrm{CN}$ polar groups and cooperative dipole motion.

\section{Conflicts of interest}

There are no conflicts to declare.

\section{Acknowledgements}

The authors thank for their financial supports of the Hassan II Academy of Science and Technology and the International Institute for Multifunctional Materials for Energy Conversion-IIMEC (Texas, USA). The authors thank also Mrs. P Khodaparast and H. B. Atitallah from Department of Mechanical and Nuclear Engineering (Pennsylvania State University) for DMA and dielectric measurements, and Pr. V. Castelvetro from the University of Pise for his fruitful discussions about emulsion polymerization and NMR. Tosoh Finechemical Corporation is also acknowledged for the free gift of 2,2,2-trifluoroethyl methacrylate (MATRIF). 


\section{Note and references}

1 (a) H. Nalwa, Handbook of Low and High Dielectric Constant Materials and Their Applications, Academic Press, London, 1999. (b) K. Müller, I. Paloumpa, K. Henkel and D. Schmeisser, J. Appl. Phys., 2005, 98, 056104. (c) R. C. G. Naber, C. Tanase, P. W. Blom, F. J. Touwslager, S. Setayaesh and D. M. de Leeuw, Nat. Mater., 2005, 4, 243-248.

2 R. Gerhard-Multhaupt, Ferroelectrics, 1987, 75, 385-392.

3 H. Gilbert, F. F. Miller, S. J. Averill, R. F. Schmidt, F. D. Stewart and H. L. Trumbull, J. Am, Chem. Soc., 1954, 76, 1074-1076.

4 A. B. Conciatore, L. E. Trapasso and R. W. Stackman, Vinylidene Cyanide Polymers, Encycl. Polym. Sci. Techn., $1^{\text {st }}$ ed, Wiley, New-York, 1971, 14.

5 S. Miyata, M. Yoshikawa, S. Tasaka and M. Ko, Polym., J. 1980, 12, 875-882.

6 S. Tasaka, K. Miyasato, M. Yoshikawa, S. Miyata and M. Ko, Ferroelectrics., 1984, 57, 267-278.

7 J. S. Harrison and Z. Ounaies, Piezoelectric Polymers, NASA/Cr 2001-21142. ICASE, 2001, Report No. 43.

8 H. Kaji, N. Miura and K. Shmidt-Rohr, Macromolecules, 2003, 36, 6100-6113.

9 H. Hui-Lin, Y. Wei-Chang, L. Ya-Lien and Y. Tri-Rung, Appl. Phys. Lett., 2007, 91, 23501-23505.

10 D.Y. Zhou, G.Z. Wang, W.S. Li, G.L. Li, C. L. Tan, M.M. Rao and Y.H. Liao, J. Power Sources., 2008,184, 477-480.

11 J. P. Montheard, A. Mesli, A. Belfkira and M. Raihane and Q.T. Pham, Macromol. Reports., 1994, A31, 1-8.

12 J. P. Montheard, A. Zerroukhi, I. Ouillon, M. Raihane and Q. T. Pham, J. Macromol. Sci. Part A: Pure. App. Chem., 1997, 34, 291-313.

13 M. Arous, A. Kallel, H. Kaddami, M. Lahcini, A. Belfkira and M. Raihane, J. Appl. Polym. Sci., 2009, 114, 1094-1104.

14 M. Raihane, A. Zerroukhi, H. Kaddami, M. Lahcini and G. Boiteux, Polym. Int., 2013, 62, 684-692.

15 T. F. Way and Hall Jr, HK, Polym. Bull., 1990, 24,151-156.

16 H. K. Hall Jr, A. B. Padias, G. Chu, H. Y. Lee, I. Kalnin, M. Sansone and G. J. Breckenridge, J. Polym. Sci. Part A: Polym. Chem., 1992, 30, 2341-2347. 
17 J. G. Drobny, Technology of Fluoropolymers, CRC Press, Boca Raton, FL, 2014.

18 J. Gardiner. Aust. J. Chem., 2015, 68, 13-22.

19 S. Ebnesajjad, Expanded PTFE Applications Handbook: Technology, Manufacturing and Applications, Elsevier Science, Norwich, New-York, 2016.

20 Chapter 20, Dielectric Fluoropolymers, M. Raihane and B. Ameduri, in: Handbook of Fluoropolymer Science and Technology, D. W. Smith, S. T. Iacono, and S. S. Iyer, Eds. Wiley, New-York, 2014, 451-494.

21 B. Ameduri and H. Sawada, Fluorinated Polymers Applications, The Royal Society of Chemistry, Oxford, UK, 2017, 2, 396.

22 B. Ameduri, Chem. Eur. J., 2018, 24, 18830-18841.

23 W. Yao, Y. Li and X. Huang, Polymer., 2014, 55, 6197-6211.

24 B. Boutevin and Y. Pietrasanta, Les Acrylates et Polyacrylates Fluorés, Erec, Paris, 1989.

25 V. Kumar, J. Pulpyte, H. Rauscher, I. Mannelli, F. Rossi and F. Arefi-Khonsari. Plasma Process Polym., 2010, 7, 926-938.

26 S. D. Xiong, X. L. Guo, L. Li, P. K. Wu and Z.S. Xu, Chu, J. Fluorine Chem, 2010, 131, 417-425.

27 K. Edelmann, A. Reiche, B. Sandner, J. Marstalerz and H. Müller, Polymer., 2005, 46, 407-417.

28 M. Obata, N. Matsuura, K. Mitsuo, H. Nagai, K. Asai, M. Harada, S. Hirohara, M. Tanihara and S. Yano, J. Polym. Sci. Part A: Polym. Chem., 2010, 48, 663-670.

29 E. Alyamac and M. D. Soucek, Prog. Org. Coat., 2011, 71, 213-224.

30 A. H. Xu, L.Q. Zhang, J.C. Ma, Y.M. Ma, B. Geng and S.X. Zhang, J. Coat. Technol. Res., 2016, 13, 795-804.

31 J. M. Cracowski, V. Montembault, I. Hardy, D. Bosc, B. Ameduri and L. Fontaine, J. Polym. Sci. Part A: Polym. Chem., 2008, 46, 4383-4391.

32 S. Koizumi, K. Tadano, Y. Tanaka, T. Shimidzu, S. Kutsumizu and S. Yano, Macromolecules., 1992, 95, 6563-6567.

33 H. Fröhlich, Theory of Dielectrics, Clarenton Press, Oxford, 1958.

34 M. Raihane and B. Ameduri, J. Fluorine. Chem, 2006, 127, 391-399.

35 A. Meskini, M. Raihane, B. Ameduri, C. Hakme, D. Sage, I. Stevenson, G. Boiteux, G. Seytre and H. Kaddami, Eur. Polym. J., 2009, 45, 804-812. 
36 M. Raihane, V. Castelvetro, S. Bianchi, S. Atlas and B. Ameduri, J. Polym Sci. Polym Chem., 2010, 48, 4900-4908.

37 V. Castelvetro, M. Raihane, S. Bianchi, S. Atlas and I. Bonaduce, J. Polym. Deg. Stab., 2011, 96, 204-211.

38 V. Castelvetro, S. Capaccioli, M. Raihane and S. Atlas, Macromolecules, 2016, 49, 51045114.

39 (a) P. A. Lovell and M. S. El-Aasser, Emulsion polymerization and emulsion polymers, John Wiley and sons, New York, 1997. (b) G. Odian, Principles of Polymerization, Chapter 4, Emulsion Polymerization, $4^{\text {th }}$ edition, New-York, John Wiley \& Sons, Inc, 2004,350-372.

40 (a) C. S. C. Thickett and R. G. Gilbert, Polymer., 2007, 48, 6965-6991. (b) T. Zhang, R.A. Sanguramath, S Israel and S. Silverstein, Macromolecules, 2019, 52, 5445-5479

41 (a) J. M. Asua, J. Polym. Sci. Part A: Polym. Chem., 2004, 42, 1025-1041. (b) M. F. Cunningham, Progress in Polymer Science., 2008, 33 (4), 365-398.

42 F. Guo, S. Aryana, Y. Han and Y. Jiao, Appl. Sci., 2018, 8, 1696; doi:10.3390/app8091696.

43 A.N. Generalova and V.P. Zubov, Coll. Surfaces B: Biointerfaces., 2018, 166, 303-322.

44 N. M.B.Smeets, S. Imbrogno and S. Bloembergen, Carbohyd. Polym, 2017, 173, 233-252.

45 M. M. Zagho, E. A. Hussein and A. A. Elzatahr. Polymers., 2018, 10, 739; doi:10.3390/polym10070739

46 Q.T. Pham, R. Petiaud, H. Waton, and N.F. Lauros-Darricades, Proton and Carbon NMR Spectra of Polymers, Prenton Press, New-York, 1991.

47 M. Fineman and S.D. Röss. J. Polym. Sci., 1975, 5(2), 259.

48 T. Kelen and F. J. Tüdos, Macromol. Sci. Chem. A., 1975, 9(1), 1

49 F. Boschet, G. Kostov, B. Ameduri, T. Yoshida and K. Kawada, J. Polym. Sci. A: Polym., 2010, 48, 1029-1037.

50 G. F. Estevez, O. V. Lizama, D. Z. Silva, L. Agüero and I. Katime, Adv. Mat. Lett., 2013, 4(7), 534-542

51 S, Igarashi. J. Polym. Sci. Polym. Lett. Ed., 1963, 1, 359-363.

52 C. W, Pyun, J. Polym. Sci. Part A: Polym. Chem.,1970, 2, 1111-1126.

53 D.Y. Zhou, G.Z. Wang, Li. WS, Li, GL. Tan, C.L. Rao, M.M and Y. HLiao, J. Power 
Sources., 2008,184,477-480.

54 S. Atlas, M. Raihane, M. Lahcini, A. Hult, M. Malkoch and B. Ameduri, J. Polym. Sci. A: Poly. Chem., 2013, 51, 3856-3866.

55 T.G. Fox, Bull. Am. Phys. Soc, 1956, 1, 123.

56 Y. Mori, H. Sumi, T. Hirabayashi, Y. Inai and K. Yokota, Macromolecules, 1994, 27, 1051-1056.

57 O. Olabisi, L.M. Robeson and M.T. Shaw, Polymer-Polymer Miscibility, Academic Press, New-York, 1979.

58 W. J. Mac Knight, FE. Karasz and J. R. Fried, Polymer Blend, Academic Press, NewYork, 1978, 1.

59DS. Kaplan, J. App. Poly. Sci., 1976, 20, 2615-2629.

60 N.G. McCrum, B.E. Read and G. Williams, Anelastic and Dielectric Effects in Polymeric Solids, Wiley, New-York, 1991.

61 Y. Shida and K. Yamafuji, Coll. Polym. Sci., 1961, 177, 97-116.

62 K. Schroter, R. Unger, S. Reissig, F. Garwe, S. Kahle, M. Beiner and E. Donth, Macromolecules, 1998, 31, 8966-8972.

63 S.C. Kuebler, D.J. Schaefer, C. Boeffel, U. Pawelzik, and H. W. Spiess, Macromolecules, 1997, 30, 6597-6609.

64 M. Wind, R. Graf, A. Heuer and H.W. Spiess, Phys. Rev. Lett., 2003, 91, 155702.

65 K. Tadano, Y. Tanaka, T. Shimizu and S. Yano, Macromolecules, 1999, 32, 1651-1660.

66 E. Baer and L. Zhu, Macromolecules, 2017, 50, 2239-2256.

67 T. Furukawa, K. Nakajima and N. Koizumi, Japan. J. Appl. Phys., 1987, 26, 1039

68 T. Furukawa, M. Date, K. Nakajima, T. Kosaka and I. Seo, Japan. J. Appl. Phys., 1986, 25, 1178-1182.

69 D. Zou, S. Iwasaki, T. Tsutsui, S. Saito, M. Kishimoto and I. Seo, Polymer, 1990, 31, 1888- 1893.

70 S. M. R. Billah. Chapter "Dielectric Polymers" in "Functional Polymers". Editors, M. A. J. Mazumder, H. Sheardown and A. Al-Ahmed, Springer Nature, Basel, 2019, pp. 1-49. https://doi.org/10.1007/978-3-319-92067-2_8-1.

71 F. Kremer and A. Schönhals, Broadband Dielectric Spectroscopy, Springer-Verlag, Berlin, 2003.

72 C.J.F. Böttcher and P. Bordewijk, Theory of Electric Polarization, $2^{\text {nd }}$ ed, Elsevier, 
Amsterdam, 1978, 2.

73 AF, Thünemann, Macromolecules., 2000, 33, 1790-1795.

74 M. Schwarz, LA. Kitchman, RW. Tucker and E.R. Nelson, J. Chem. Eng. Data., 1970, 15, 341-346.

75 IEEE Guide for the statistical analysis of electrical insulation breakdown data IEEE Std 930-2004 (Revision of IEEE Std 930-1987).

76 C. Chauvet and C. Laurent, IEEE Transactions on Electrical Insulation, 1993, 28, 18-29.

77 W. Weibull, J. Appl. Mech., 1951, 18, 293-297.

78 T.W. Zhu, C. Qian, W.W. Zheng, R.X. Bei, S.W. Liu, Z.G. Chi, X.D. Chen, Y. Zhang and J. R. Xu, RSC Adv., 2018, 8, 10522-10531.

79 S. Diaham, S. Zelmat, M.-L. Locatelli, S. Dinculescu, M. Decup and T. Lebey, IEEE

Transactions on Dielectrics and Electrical Insulation., 2010,17, 18 -27.

80 M. Leda, M. Naga and M. Hikita, IEEE Transactions on Dielectrics and Electrical Insulation., 1994, 5, 934-945.

81 M. Hikita, I. Kanno, M. Ieda. I. Ishino, S. Doi and G. Sawa , IEEE Transactions on Electrical Insulation., 1987, 22, 175-79.

82 B. Hilczer and S. Malecki, J. Electrets: Studies in Electrical and Electronic Engineering, Elsevier, New York, 1986, 14, p.19. 